\title{
URSI National Committee Report, XIV General Assembly, Tokyo, September, 1963: Commission 5. Radio and Radar Astronomy
}

Review of developments occurring within the United States of America in the field of radio and radar astronomy $1960-1963$.

University of Alabama

Cornell University

Air Force Cambridge Research Laboratories

Sagamore Hill Radio Observatory

Collins Radio Company

Carnegie Institution of Washington

Department of Terrestrial Magnetism

University of Florida

Harvard College Observatory

Harvard Radio Astronomy Station

Radio Astronomy Group and Space Radio Project

Radio Meteor Project

University of Illinois

Jet Propulsion Laboratory
Massachusetts Institute of Technology

Lincoln Laboratory

University of Michigan

National Aeronauties and Space Ageney

Goddard Space Flight Center

National Bureau of Standards

National Center for Atmospheric Research

High Altitude Observatory

National Radio Astronomy Observatory

Ohio State University Radio Observatory

Stanford Radio Astronomy Institute

University of Texas

U.S. Naval Research Laboratory

Yale University

\section{University of Alabama, University, Ala.}

Work has continued in the field of millimeter wavelength radiometry, including development of a model for thermal emission from the lunar surface, a further investigation of the crystal-audio radiometer performance, and a study of the absorption by molecular oxygen in the atmosphere.

Experiments on thermal radiation from the moon yielded more detailed data of lunar temperature as a function of lunar phase angle and during eclipses. A solution of the heat conduction equation consistent with infrared data was obtained for various assumed models and thermal parameters of the surface [Tyler, 1962].

The performance of a crystal-audio radiometer in experiments where extreme sensitivity is not needed was investigated. The minimum detectable temperatures were compared with predictions from the spectral analysis [Copeland, 1962].

The current theories of mechanism of absorption by atmospheric molecular oxygen in the wavelength region between 1 and $10 \mathrm{~mm}$ were surveyed. Shortperiod fluctuations in atmospheric absorption, possibly correlated with variations in the earth's magnetic field or other external factors, have been suspected. The probable effects of time-varying external fields, Zeeman splitting, and statistical orientations of the oxygen molecule in the magnetic field were analyzed. None of these factors appear to explain the suspected variations [Mitchell, Dozier, and Coulter, 1962].

\section{References}

Copeland, J. (1962), The crystal-video radiometer, U.S. Army Ordnance Missile Command Report RR-TM-62-4.

Mitchell, F. H., J. B. Dozier, and P. W. Coulter (1962), Opacity of the atmosphere at millimeter wavelengths, University of Alabama Research Institute Report FTR-1.

Tyler, Warren C. (1962), The experimental measurement and theoretical interpretation of thermal radiation from the lunar surface, Doctoral Thesis, University of Alabama, U.S. Army Ordnance Missile Command Report RN-2H4N.

\section{Cornell University, Ithaca, N.Y.}

Two hundred Mc/s polarization measurements of solar bursts have continued and continued to show a fraction of Type III bursts to be weakly linearly polarized.

Cornell has been constructing on a contract from ARPA and the Air Force Cambridge Research Center a thousand-foot antenna equipped with transmitter and receiver at $430 \mathrm{Mc} / \mathrm{s}$ as an ionospheric and planetary radar. This large facility is expected to be ready in the summer of 1963 .

\section{Bibliography}

Akabane, K., and M. Cohen (1961), Polarization measurements of Type III bursts and Faraday rotation in the corona, Ap. J. 133, 258.
Cohen, M., (1960), High-frequency radar echoes from the sun, Proc. IRE 48, 1479.

Cohen, M., (1961), Microwave polarization and coronal magnetic fields, Ap. J. 133, 978.

Cohen, M., (1961) Radiation in a plasma I. Cerenkov effect, Phys. Rev. 123, 711.

Cohen, M., (1962), Radiation in a plasma II. Equivalent sources, Phys. Rev. 126, 389.

Cohen, M., (1962), Scattering and conversion cross-sections in inhomogeneous plasma, J. Geophys. Res. 67, 2729.

Cohen, M., and M. Dwarkin (1961), Perpendicular inter ections with a dipole field, J. Geophys. Res. 66, 411.

Gordon, W. E., and L. M. LaLonde (1961), The design and capabilities of an ionospheric probe, IRE Trans. Ant. Prop. 1\%. 


\section{Air Force Cambridge Research Laboratories Sagamore Hill Radio Observatory, Bedford, Mass.}

The basic instrument used in studies of the sun, the moon, and atmospheric parameters was the $84-\mathrm{ft}$ equatorially mounted parabola. Recent additions to the antenna equipment, of the Radio Astronomy Branch, have included an alt-az 150-ft antenna (rotatable only in azimuth until a servo drive is installed at the end of 1963) and a log periodic in terferometer (spacings available $90 \mathrm{~m}, 180 \mathrm{~m}$, and $270 \mathrm{~m}$ on East-West baseline). An 8 - $\mathrm{ft}$ parabola is used for $3 \mathrm{~cm}$ solar measurements, on a routine basis. Smaller antennas are used for satellite and cosmic noise absorption measurements. Radiometers are available from $30 \mathrm{Mc} / \mathrm{s}$ to $9300 \mathrm{Mc} / \mathrm{s}$.

\subsection{Solar Studies}

\section{a. Occultation of the Crab Nebula}

In June 1961 and 1962, observations were made of the occultation of the Crab Nebula by the solar corona. The scattering process was observable at $1190 \mathrm{Mc} / \mathrm{s}$ and $3000 \mathrm{Mc} / \mathrm{s}$ and its anisotropy on either side of solar disk was revealed. At a distance of 5 solar radii, the decrease in temperature of the source at $3000 \mathrm{Mc} / \mathrm{s}$ was evaluated as 18 percent; the angular diameter of the scattered radiation was 22 min of arc, while the same parameters, at a distance of 7.5 solar radii corresponding to $1190 \mathrm{Mc} / \mathrm{s}$, were 37 percent and $23 \mathrm{~min}$ of arc, respectively. The scale of irregularity at a distance of 5 solar radii was evaluated on the basis of the June 14 record on $S$-band and the value was estimated at $0.5 \mathrm{~km}$. The program has been carried out by $\mathrm{S}$. Basu and J. Castelli.

\section{b. Solar Eclipse Results}

Observations of the October 2, 1959, and the February 15, 1961, eclipses have been analyzed, with careful attention paid to radio heliograms taken at frequencies near those of the eclipse radiometers. The heliograms, supplied by Stanford University and CSIRO, have shown the presence of spots and plage regions near both limbs during both eclipses. Unwarranted models of limb brightening could thus be avoided, but the opportunity for calculating the height of the emitting layers above the sunspots was presented.

The heights, deduced from the slopes of the temperature changes, were 10,000 to $16,000 \mathrm{~km}$ at 9700 $\mathrm{Mc} / \mathrm{s}$ (1961), 13,000 to 25,000 at $1300 \mathrm{Mc} / \mathrm{s}$ (1959), 20,000 to $25,000 \mathrm{~km}$ at $1270 \mathrm{Mc} / \mathrm{s}(1961)$, and 26,000 to 35,000 at $1300 \mathrm{Mc} / \mathrm{s}$ (1959). Angular diameters of the spots were double checked by comparison in first to second contact records, with third to fourth contact. One spot in the 1961 eclipse measured 0.75 min of arc at $9700 \mathrm{Mc} / \mathrm{s}$ and $0.9 \mathrm{~min}$ of arc at 1270 $\mathrm{Mc} / \mathrm{s}$. The brightness temperatures of this region were $1.5 \times 10^{5}{ }^{\circ} \mathrm{K}$ at $9700 \mathrm{Mc} / \mathrm{s}$ and $9 \times 10^{5}{ }^{\circ} \mathrm{K}$ at $1270 \mathrm{Mc} / \mathrm{s}$. J. Castelli, R. Straka, H. Cohen, and J. Aarons performed the observations and the analysis.

\author{
c. VLF Envelope of Solar Bursts
}

A study of the very low frequency envelope spectra of solar bursts has been undertaken to gather information on the generating mechanism of solar radio bursts. Solar bursts were received by the $84-\mathrm{ft}$ paraboloid at $63 \mathrm{Mc} / \mathrm{s}, 113 \mathrm{Mc} / \mathrm{s}, 220 \mathrm{Mc} / \mathrm{s}, 400 \mathrm{Mc} / \mathrm{s}$, $1190 \mathrm{Mc} / \mathrm{s}$, and $3000 \mathrm{Mc} / \mathrm{s}$. The signal was amplified and then detected, and the detected signal was recorded on a FM tape recorder. The magnetic tape recorded the envelope of the RF signals from 0 to $500 \mathrm{c} / \mathrm{s}$, in the initial stages, and over 0 to 1250 $\mathrm{c} / \mathrm{s}$ later. The RF noise, from the laboratory noise generator, was also recorded on the tape through identical receivers; these records served as a norm of analysis. The recorded signal was then analyzed on a spectrum analyzer to yield the envelope spectra. Since the IF bandpass is square and the law of detector is square over the range of signals recorded, the envelope spectra of a random noise is expected to be flat over the VLF band, which is very small compared to the IF bandwidth. The envelope of the laboratory noise generator was found to be flat, in agreement with the theory. An analysis of the burst records showed that meter wave bursts, of Type IV, and the centimeter wave bursts yield a flat spectra. Other types of meter wave bursts have varying spectral density over the VLF band, and there are cases where a narrow band structure could be seen with a duration of 10 to 15 sec.

The hypothesis advanced is that a coronal disturbance can generate hydromagnetic waves over VLF range and may be transformed into EM waves when it encounters a coronal inhomogeneity. The VLF waves may be coupled, in a nonlinear way, with the high-frequency plasma waves and introduce a VLF modulation on the solar bursts. This program is being carried out by $\mathrm{S}$. Basu.

\subsection{Hydrogen-Line Observations}

The mass and velocity distribution of neutral hydrogen in three nearby 11 Sc galaxies (M33, M101, and IC342) have been studied, using the Harvard 60-ft antenna with the maser receiver. In addition, observations of the region North of the galactic latitude $b^{\prime \prime}=80^{\circ}$ were made to show smaller scale irregularities than previously have been shown in the North galactic polar gap. Some very narrow emission lines have been found in this region. $\mathrm{N}$. Dieter is working on these observations.

\subsection{Sky Temperature Measurements}

Effective sky temperature measurements were made on $10 \mathrm{~cm}$ wavelengths, using an 8 -ft parabolic antenna and a horn antenna. The antenna half power beamwidths were $3^{\circ}$ and $6.9 \times 8.3^{\circ}$ respec- 
tively. Temperatures, as a function of antenna elevation angle and time of day, were measured with the steerable parabolic antenna. The horn was pointed to zenith, in a fixed position, and recorded the high angle temperature changes due to frontal passages and other weather changes. Preliminary analysis shows that the sky temperatures went through a cyclic maximum every five to six days, with possible changes during the daily interval of as much as $20^{\circ} \mathrm{K}$ at a given elevation angle. The profile of antenna temperature, as a function of elevation, varied very little from day to day, although the overall temperatures of the day were higher than those of adjoining days. R. Straka conducted the measurements.

\subsection{Flux Measurements}

A combination of antenna pattern and efficiency measurements and the use of the flux of Cass A, as a standard, have led to improved accuracy in values of solar temperature and lunar disk temperatures. Utilizing Ko's analysis to correct antenna temperatures, using the flux measurements of Cass $A$ as a standard, lunar temperatures of $230{ }^{\circ} \mathrm{K}$ at 1200 $\mathrm{Mc} / \mathrm{s}$ and $223^{\circ} \mathrm{K}$ at $3100 \mathrm{Mc} / \mathrm{s}$ were obtained. For a period of two weeks in April 1962, comparison of solar observations at $94,000 \mathrm{Mc} / \mathrm{s}, 9180 \mathrm{Mc} / \mathrm{s}, 2965 \mathrm{Mc} / \mathrm{s}$, $3100 \mathrm{Mc} / \mathrm{s}, 1200 \mathrm{Mc} / \mathrm{s}, 400 \mathrm{Mc} / \mathrm{s}$, and $225 \mathrm{Mc} / \mathrm{s}$ were made. The $S$-band measurements were compared with Covington's data at $2800 \mathrm{Mc} / \mathrm{s}$ and found to be in good agreement. A simple technique exists, then, for measuring antenna efficiency, as well as pattern, by utilizing flux measurements of Cass $A$ as a standard; or one can use the Covington $10 \mathrm{~cm}$ solar values, applying pattern measurements plus corrections on the forms of the pattern to obtain the resulting antenna efficiency. J. Castelli performed the experiment.

\subsection{Atmospheric Studies}

A large part of the effort of the Radio Astronomy Branch has been devoted to the study of tropospheric and ionospheric scintillation [Kidd and Mullen] and to electron density studies [Whitney and Klobuchar]. The observations for the former studies have included the discrete sources and satellite transmissions; observations for the latter studies have included lunar reflections and satellite signals. Tropospheric scintillations, observable almost en tirely at low angles of elevation, are characterized by long period scintillations (1 min); ionospheric scintillations recorded at frequencies to $1300 \mathrm{Mc} / \mathrm{s}$, during periods of intense magnetic storms, are of shorter periods. The effects on coherence across an aperture of the size of irregularities, latitude dependence, and angle of elevation are being studied. During periods of intense magnetic storms the $60 \mathrm{Mc} / \mathrm{s}$ correlation distance, on the ground, may be as small as $5 \mathrm{~m}$. Some of the earlier angle of elevation studies of scintillation index are being reviewed; there are serious doubts concerning their interpretation, because of the use of selected sites and Cass and Cygnus measurements.
Lunar reflection studies were performed in cooperation with the Jodrell Bank Experimental Station. Records of the Jodrell Bank transmissions at 150 $\mathrm{Mc} / \mathrm{s}$ were taken at both sites and ionospheric gradients compared. Similar work, using transmissions of the U.S. Signal Corps, was done in cooperation with Dr. Daniels of the U.S. Signal Corps and Dr. Webb of the University of Illinois. Satellite work on electron density variations is being done in cooperation with a European group of stations under NATO sponsorship.

\subsection{Conferences}

A working conference on the November 1960 solar terrestrial events was held at AFCRL. Observations and analysis of (1) cosmic ray variation, (2) lunar reflection studies of electron density variations, (3) cosmic noise absorption, (4) solar optical and radio events, and (5) ionospheric propagation were discussed. The aim was exchange of knowledge between disciplines. At the least, the observational material was plainly set out; hopefully the total picture of solar events and resultant terrestrial effects was made meaningful. A report of AFCRL observations, with the subject matter ranging from $3 \mathrm{~cm}$ heliograms of the sun to cosmic ray satellite observations, has been prepared by S. Silverman and J. Aarons.

The Advanced Study Institute of Corfu, Greece, under NATO sponsorship, held a conference on "Radio Astronomical and Satellite Studies of the Atmosphere." Radio star scintillation, Faraday rotation in the earth's atmosphere by lunar reflection and satellite transmissions, and sudden ionospheric disturbance were some of the subjects studied. The proceedings have been issued with J. Aarons as editor.

\section{Bibliography}

Aarons, J. (1960), Observatory reports, Astron. J. 65, 1-2. Aarons, J. (1961), Observatory studies, Astron. J. 66, No. 9.

Aarons, J. (compiler) (1961), Studies and measurements made of the solar eclipse of October 2, 1959, Electronics Research Directorate, AFCRL, AF OAR.

Aarons, J. (Aug. 1961), An introduction to the sun and its effect on propagation with special reference to the November 1960 cosmic-ray flares, Electronics Research Directorate, AFCRL (presented at NATA Summer Conference, Corfu, Greece)

Aarons, J. (Nov. 1962), Sagamore Hill Radio Observatory, Astron. J. 67.

Aarons, J. (1963), Low angle scintillations of discrete sources, Project 5629, Radio Astronomical and Satellite Studies of the Atmosphere (North Holland Publishing Company).

Aarons, J., W. Barron, A. Egeland, and G. Gustafsson (1962), Band emissions at gyro frequencies of ionospheric ions and hiss frequencies, AFCRL Report.

Aarons, J., S. Basu, W. Kidd, and R. Allen (1961), Very low frequency modulation of discrete frequency solar noise bursts, Nature 191, No. 4783, 56-57.

Aarons, J., and J. P. Castelli (1961), Simultaneous scintillation observations on $1300 \mathrm{Mc}$ and $3000 \mathrm{Mc}$ signals received during the solar eclipse of October 2, 1959, IRE Trans. Ant. Prop. AP-9, No. 4.

Aarons, J., J. Castelli, and W. Kidd, Rise and set of Cygnus A, Physical Society, London, England (in press).

Aarons, J., W., Kidd, H. Silverman, and H. Whitney (1962), Scintillations of radio stars and satellites during intense magnetic disturbances, Nature 193, No. 4822, 1246-1249. 
Aarons, J., J. Klobuchar, H. Whitney, and G. Kantor (1962), Irregular lunar reflection polarization changes noted in the presence of aurora, J. Geophys. Res. 67, No. 1, 111-112.

Aarons, J., and S. Silverman (1962), eds., AFCRL studies of the November 1960 solar-terrestrial events, AFCRL Research Report 62-441.

Aarons, J., H. E. Whitney, R. S. Roger, Thomson, J. Bournazei, E. Vassy, H. A. Hess, K. Rawer, N. Carrara, P. Checcacci, B. Landmark, J. Troim, B. Hultquist, and L. Liszka (1961), Atmospheric phenomena note and in simultaneous observations of 1958 (Sputnik III), Planetary and Space Science 5, No. 3, 169-184.

Basu, S., and J. Castelli, Occultation of the Crab nebula by the solar corona in June 1962, Nature (in press).

Castelli, J., H. Cohen, R. Straka, and J. Aarons (1962), Radio measurements of two total eclipses, AFCRL Research Report 62-852.

Castelli, J., and C. Ferioli (1962), Lunar thermal emission measurements, AFCRL Research Report 62-882.

Dieter, N. (1962), A search for HI in Centaurus A, Astron. J. 67, 1299 .

Dieter, N. (1962), Neutral hydrogen in IC 342, Astron. J. 6\%, 1300 .

Dieter, N. (1962), Neutral hydrogen in M101, Astron. J. 67, 1302 .

Dieter, N. (1962), Neutral hydrogen in M33, Astron. J. 6y, 1299 .

\section{Collins Radio Company, Cedar Rapids, Iowa}

Precise determinations of the mean total atmospheric refraction were made for various altitude angles from 2 to $65 \mathrm{deg}$ [Anway, 1961] by using a precision radio sextant operating at $1.85 \mathrm{~cm}$ wavelength to measure the solar altitude angle. Eleven sunrises and 39 sunsets were observed over a five-month period. A highly accurate total refraction predictor was developed [Iliff and Holt, 1962] from these measured data. Refraction predicted by this equation, utilizing only station measurements of surface atmospheric refractivity, differs from measured refraction values by less than 10 sec of are, rms above $10 \mathrm{deg}$ altitude angle. The strong linear correlation of total refraction with surface refractivity, originally suggested by Bean and Cahoon on theoretical grounds, was verified experimentally [Holt and Iliff, 1962]. Some less precise measurements of total refraction were made simultaneously at $8.7 \mathrm{~mm}$ and $1.85 \mathrm{~cm}$ and calculations of this quantity were made from meteorological profiles obtained at the same time and place [Phillips and Anway, 1961.] In addition, measured and calculated atmospheric attenuations were compared at both wavelengths. The comparisons of measurement and theory were very good at both wavelengths.

Solar temperature measurements were made at $8.7 \mathrm{~mm}$ and $1.85 \mathrm{~cm}$ and yielded values for the source temperature of $8808{ }^{\circ} \mathrm{K}$ and $11,831{ }^{\circ} \mathrm{K}$ respectively [Steward, Anway, and Hodgin, 1961]. Solar activity data at $1.85 \mathrm{~cm}$ collected during sunspot maximum [Anway, Joy, and Hodgin, 1961] have been compared with optical and $10 \mathrm{~cm}$ activity. During the observing period there were 123 optical flares reported, 82 radio bursts observed at $10 \mathrm{~cm}$, and 32 events observed at $1.85 \mathrm{~cm}$. The mean duration of the optical flares was $39 \mathrm{~min}$ while that at $1.85 \mathrm{~cm}$ was only $5 \mathrm{~min}$. These results have implications for
Fleischer, R., M. Oshima, T. Roark, R. Straka, and M. DeJong (1962), Effects of the atmosphere on radio astronomical signals, Rensselaer Polytechnic Institute, AFCRL$62-311$.

Galloway, J. (1961), A review of the theory of the absorption of microwaves by the atmospheric gas-oxygen, Radio Astronomy Branch, Propagation Sciences Laboratory, Electronics Research Directorate, AFCRL, AF OAR.

Gustafsson, G., A. Egeland, and J. Aarons (1960), Audiofrequency electromagnetic radiation in the auroral zone, J. Geophys. Res. 65, No. 9, 2749-2758.

Malik, C., J. Aarons, and H. Poeverlein (1960), Backscatter experiments during the total eclipse of October 2, 1959, J. Geophys. Res. 65, No. 10, 3241-3247.

Straka, R., P. Elkins, and H. Strick, (1962), Decametric wavelength absorption resulting from the July 9, 1962, nuclear detonation, Nature 196, 156.

Taylor, G., H. Whitney, and J. Klobuchar (1962), Bistatic lunar radar measurements of large scale variations in ionospheric electron content, AFCRL Research Note 62360 .

Whitney, H. (1963), Radio Astronomy Instrumentation, ERD-CRR-3-TM-62-51 (1962), Radio astronomical and satellite studies of the atmosphere (North Holland Publishing Company).

Whitney, H., H. Strick, J. Aarons, and J. Mott (1960), Sudden amplitude variations of Sputnik III signals, J. Geophys. Res. 65, No. 12, 4210-4212.

radiometric celestial-navigation purposes and a report covering this analysis is in process.

Some measurements of lunar temperature and its variation over a lunation were made at $8.7 \mathrm{~mm}$ and $1.85 \mathrm{~cm}$ [Stewart, Anway, and Hodgin, 1961]. Maximum temperatures were $239{ }^{\circ} \mathrm{K}$ and $195{ }^{\circ} \mathrm{K}$ and the minimum temperatures observed were $153^{\circ} \mathrm{K}$ and $125^{\circ} \mathrm{K}$ for the two wavelengths respectively. Attempts to establish a connection between lunar tracking errors and lunar phase were not conclusive. Significant errors were noted at $8.7 \mathrm{~mm}$ and $1.85 \mathrm{~cm}$ but the form of the relationship of these errors to lunar phase is not yet determined (Stewart, Anway, and Hodgin, 1961; Anway, Joy, and Hodgin, 1961).

A high performance $\left(\Delta T=0.034 / \tau^{1 / 2}{ }^{\circ} \mathrm{K} / \sec ^{1 / 2}\right.$ for the d-c mode) $1.85 \mathrm{~cm}$ radio-telescope is nearing completion. This system, utilizing a low noise traveling wave tube amplifier, will be used in $8-\mathrm{ft}$ and $60-\mathrm{ft}$ diam antennas for observations of atmospheric emission and refraction fluctuations and solar, lunar, and planetary phenomena.

A theoretical and experimental investigation of atmospheric emission in the 5 to $6 \mathrm{~mm}$ wavelength region was performed, and further experimental work is being planned (Anway, 1962a: Anway, 1962b).

\section{Bibliography}

Anway, A. C. (1961), The empirical determination of total atmospheric refraction at $2 \mathrm{~cm}$ wavelengths by radiometric means, URSI Fall Meeting.

Anway, A. C. (1962a), Antenna temperature gradients of atmospheric oxygen emission at wavelengths near $6 \mathrm{~mm}$, URSI U.S. Annual Meeting.

Anway, A. C. (1962b), Microwave emission from the atmosphere at wavelengths near $6 \mathrm{~mm}$, NEREM Record 4, 138. 
Anway, A. C., R. D. Joy, and D. M. Hodgin (1961), Final report for electronic sextant $\mathrm{AN} / \mathrm{SRN}-4(\mathrm{XN}-1)$, Collins Research Report CRR-204, III.

Holt, J. M., and W. R. Iliff, The correlation of measured total atmospheric refraction with surface refractivity, URSI U.S. Annual Meeting.

Iliff, W. R., and J. M. Holt (1962), The prediction of total atmospheric refraction at low elevation angles, URSI U.S. Annual Meeting.
Phillips, G. D., and A. C. Anway (1961), Comparison of measured and calculated total atmospheric refraction and atmospheric transmission coefficient at $8.7 \mathrm{~mm}$ and 1.85 em, URSI Fall Meeting.

Stewart, C., A. C. Anway, and D. M. Hodgin (1961), Final report for radio sextant research program, Collins Research Report CRR-243.

\section{Carnegie Institution of Washington, Department of Terrestial Magnetism, Washington, D.C.}

Emphasis has gradually focused down to a double program at the Department of Terrestrial Magnetism:

(1) Radio hydrogen studies with the Carnegie multichannel $\mathrm{H}$-line receiver, and

(2) studies of discrete radio sources.

During 1962 a study was made of expanding hydrogen features in the vicinity of the galactic center. The observed motion agreed well with those observed by the Dutch at more northern latitudes, but in the parts of the Milky Way below the Dutch horizon additional features were found which complicated the simple model of a $3 \mathrm{kpc}$ expanding arm. Preliminary hydrogen line studies of M31 and M33 were carried out using the $60-\mathrm{ft}$ dish at Derwood, Md., and the multichannel spectrograph, in preparation for use of the spectrograph with larger dishes. During late 1962 and early 1963 the number of channels was expanded from its original 54 to a present total of 90 channels and the trailer containing the equipment was moved to the National Radio Astronomy Observatory at Green Bank to make observations with the 300-ft transit telescope. Successful observations were obtained at Green Bank of M31, M33, and selected regions of the galaxy. Reduction of these observations is still in progress.

A cooperative venture with the University of La Plata and the University of Buenos Aires has been proceeding for the past three years and a second multichannel hydrogen line spectrograph is well on its way to completion, and an equatorially mounted 30- $\mathrm{m}$ dish has been designed in collaboration with Stanford Research Institute. Completion of both the receiver and the dish is expected in late 1963. The dish represents a new departure in radio telescope design in which large safety features are not arbitrarily inserted to obtain a dish ten times more rigid than required for the wavelength of interest. As one moves into larger dishes this luxury can no longer be afforded and it is necessary to design more quantitatively. A trial dish of the same design but transit mounted is being constructed now at our Derwood field station and should be completed by mid-1963. Experience with this "maximum tolerable deflection" dish should be of use to other institutions interested in large inexpensive paraboloids.

\section{University of Florida, Gainesville, Fla.}

The University of Florida Radio Observatory is engaged in long-wavelength radiofrequency studies of the planets. In addition to the main station at Gainesville, Fla., a field station near Santiago, Chile, has been in operation since 1960. Synoptic monitoring of the decameter signals from Jupiter is maintained on a daily basis from both stations over a frequency range of 5 to $53 \mathrm{Mc} / \mathrm{s}$. Polarization measurements are made at 16 and $22 \mathrm{Mc} / \mathrm{s}$ and spectral data are obtained by means of a sweep-frequency receiver at Gainesville.

The data have established the existence of three or more, probably four, main decameter sources on Jupiter, and have yielded a precise rotational period for these sources which is most likely that of the solid planet itself. Statistical analysis has yielded the spectral index and mean rate of radiation as a function of frequency, and has indicated that the Jovian outbursts may be associated with solar activity both in a long-term and a short-term sense. The polarization of the signals is predominantly left-hand elliptical in both hemispheres of the earth, although right-hand polarization is observed more frequently at $16 \mathrm{Mc} / \mathrm{s}$ than at $22 \mathrm{Mc} / \mathrm{s}$. There apparently is some statistically significant variation in the polarizaations of the signals from the several sources, as well as variations in relative source activity from year to year. Simultaneous high-speed recordings made from two terrestrial hemispheres show significant modification of the signals by the earth's ionosphere. Spectral studies indicate that the bursts have bandwidths of from a few tenths of a megacycle per second to several megacycles per second, and that the noise storm centers drift both upward and downward in frequency. Theoretical studies suggest several possible mechanisms for the outbursts, including cyclotron radiation from trapped electrons bunched in the Jovian magnetosphere. Many of the empirical aspects of the signals can be explained if it is assumed that they escape by means of fieldalined ion ducts in the vicinity of the Jovian magnetic poles. 
Observations of Saturn have yielded a number of instances of possible weak signals of brief duration, although these have not been confirmed and cannot be regarded as well-established. Observations of Venus and Mars have given negative results to date. In November of 1961 observations were made of the close approach of Comet Seki 1961h, with negative results.

\section{Bibliography}

Carr, T. D., The possible role of field-aligned ducts in the escape of decameter radiation from Jupiter, Proceedings of Conference on Jupiter, NASA Goddard Institute for Space Studies (in press).

Carr, T. D., A. G. Smith, and H. Bollhagen (1960), Evidence for the solar corpuscular origin of the decameter wavelength radiation from Jupiter, Phys. Rev. Letters 5, 418.

Carr, T. D., A. G. Smith, H. Bollhagen, N. F. Six, and N. E. Chatterton (1961), Recent decameter wavelength observations of Jupiter, Saturn, and Venus, Ap. J. 354, 105.

Carr, T. D., A. G. Smith, N. Chatterton N. F. Six, and H. Bollhagen (1960), Observations of radio noise storms on Jupiter during the 1960 apparition, Astron. J. 65, 485.

Carr, T. D., A. G. Smith, C. S. Higgins, H. Bollhagen, and J. May, The statistical spectrum of Jupiter at decameter wavelengths, Astron. J. (in press).

Carr, T. D., A. G. Smith, and R. J. Leacock (1962), Polarization of the radiation from Jupiter at $22.2 \mathrm{Mc} / \mathrm{s}$, J. Geophys. Res. 67, 3548 .

Carr, T. D., A. G. Smith, and N. F. Six (1962), Spectral distribution of peak flux densities from Jupiter at decameter wavelengths, Bull. Am. Phys. Soc. II, 567.
Smith, A. G. (1960), Annual Report of the University of Florida Radio Observatory, 1959-1960, Astron. J. 65, 512.

Smith, A. G. (1961), Annual Report of the University of Florida Radio Observatory, 1960-1961, Astron. J. 66, 439.

Smith, A. G., Radio Astronomy, a chapter in Fundamentals of Astronautics (Prentice-Hall) (in press).

Smith, A. G., (1960), Radio Jupiter sends science data, Florida Alligator Review 2, 1 (invited popular exposition).

Smith, A. G. (1961), The radio spectrum of Jupiter, Science $\mathbf{1 3 4}, 587$

Smith, A. G., and T. D. Carr (1961), A comparison of Jupiter's radio sources with its visible markings, Quart. J. Florida Acad. Sci. 24, 185.

Smith, A. G., and T. D. Carr, Radio exploration of the planetary system (D. Van Nostrand Co.) (in press). A text written at the request of the Commission on College Physics.

Smith, A. G., and T. D. Carr (1961), Solar stimulation of the decameter wavelength radiation from Jupiter, Bull. Am. Phys. Soc. II, 465.

Smith, A. G., T. D. Carr, and N. E. Chatterton, Spectra of the decameter radio bursts from Jupiter, Proceedings of the XII International Astronautical Congress (Academic Press Inc.) (in press for early 1963).

Smith, A. G., T. D. Carr, N. E. Chatterton, and H. Bollhagen (1961), Spectral distribution of the decameter wavelength radiation from Jupiter, J. Geophys. Res. 66, 2561.

Smith, A. G., T. D. Carr, and N. F. Six, Non-thermal radiation from Jupiter in the decameter wavelength range, Proceedings of the Third Symposium on the Engineering Aspects of Magnetohydrodynamics (Gordon and Breach) (in press)

Smith, A. G., T. D. Carr, and N. F. Six, Results of recent decameter wavelength observations of Jupiter, Proceedings of the Eleventh International Colloquium on Astrophysics (in press)

\section{Harvard College Observatory Harvard Radio Astronomy Station, Fort Davis, Tex.}

\subsection{Solar Radio Burst}

During the past three years observations of solar radio bursts, taken with sweep-frequency receivers [Thompson, 1961] covering 5.5. octaves of the electromagnetic spectrum, 25 to 580 and 2100 to $3900 \mathrm{Mc} / \mathrm{s}$, have been analyzed in some detail. An analysis of the spectral Type II bursts [Maxwell and Thompson, 1962] suggests that they are caused by a disturbance being propagated along a coronal streamer, in which the electron density is approximately 10 times that of the Baumbach-Allen model corona. The radial velocity of this disturbance, deduced from a detailed examination of the frequency drift of the bursts, is estimated as 1000 to $1500 \mathrm{~km} / \mathrm{sec}$. The characteristics of the primary disturbance causing the bursts have been considered in terms of acoustic and magnetohydrodynamic waves propagated from flare regions in the vicinity of sunspots and their accompanying magnetic fields.

A detailed analysis of the characteristics of spectral Type III bursts has also been carried out [Hughes and Harkness, 1963]. On the assumption that the coronal temperature is $10^{6}{ }^{\circ} \mathrm{K}$ and that the bursts are generated in a coronal streamer where the electron density is also 10 times the Baumbach-Allen model, the frequency drift of the bursts is interpreted in terms of an outward moving disturbance, with a radia component of velocity of about $0.4 \mathrm{c}$, and with some evidence that the disturbance decelerates slightly as it moves outward. The duration and bandwidths of the bursts at different frequencies have been used to obtain estimates of the dispersion of the Type III exciters at different heights in the corona. It is found that the exciter disperses as it moves outward and that its radial extent is roughly proportional to its height above the photosphere. The characteristics of Type IV continuum radio bursts, over the frequency range 25 to $70,000 \mathrm{Mc} / \mathrm{s}$, have been reviewed [Thompson and Maxwell, 1962] and the properties of these bursts, which are believed generated by a synchrotron process, have been discussed in terms of existing data on electron energies and magnetic fields near solar flares.

A catalog of Type II and Type IV bursts, covering a 5 -year period commencing 1957 January, has been published [Maxwell, Hughes, and Thompson, 1963]. These bursts are of particular geophysical significance, since they precede the emission of high energy solar protons and the solar streams that cause geomagnetic storms. A paper concerning the statistics of solar radio bursts at sunspot maximum [Maxwell, Howard, and Garmire, 1960] gives an analysis of the total numbers of hours that the various 
spectral types of bursts occurred at various frequencies in the radio band. An analysis of the characteristics of meteor scatter bursts from distant television transmitters, as observed on sweep-frequency receivers [Thompson, 1961], showed that the duration of the scatter signals at different frequencies agreed closely with the theoretical inverse-square relation.

\subsection{Additions to Station Facilities}

During 1962, an 85-ft steerable paraboloid and a new laboratory were constructed at the station. The antenna was constructed by Blaw-Knox Company, Pittsburgh; the surface of the reflector is accurate to $1 / 32$ in. (rms); the read-out system uses digital lightbank displays.

The above research programs in solar radio astronomy and the extensions to the station facilities have been financed by the Sacramento Peak Observatory and the Geophysics Research Directorate of the U.S. Air Force.

\subsection{Cosmic Radio Sources}

A new program of observations of cosmic radio sources at $5000 \mathrm{Mc} / \mathrm{s}$ (C-band) has been undertaken with financial support from the National Science Foundation. The program of observations will concern the positions, diameters, and polarizations of discrete radio sources, and it will use a receiver with a parametric rf preamplifier. The bandwidth of the receiver is $125 \mathrm{Mc} / \mathrm{s}$ and the minimum detectable temperature is approximately $0.05^{\circ} \mathrm{K}$. A receiver whose operating frequency is $950 \mathrm{Mc} / \mathrm{s}$ and minimum detectable signal $0.2^{\circ} \mathrm{K}$ is also being used with the 85 - $\mathrm{ft}$ antenna, for search and reference purposes.

\section{References}

Boischot, A., F. T. Haddock, and A. Maxwell (1960), Spectrum of 1957 November 4 solar outburst, Ann. Astrophys. 23, 478 .

Hughes, M. P. (1961), Solar radio emissions and geophysical disturbances during July 1959, J. Geophys. Res. 66, 651.

Hughes, M. P., and R. L. Harkness (1963), Spectral observations of solar radio burst. IV. Fast-drift bursts, Ap. J. (in press).

Maxwell, A. (1960), Recent developments in solar radio astronomy, Proceedings of NAS $\mathbf{4 6}, 1260$.

Maxwell, A., W. E. Howard, and G. Garmire (1960), Some statistics of solar radio burst at sunspot maximum, J Geophys. Res. 65, 3581.

Maxwell, A., M. P. Hughes, and A. R. Thompson (1963), Catalog of Type II (Slow-drift) and Type IV (Continuum) Solar radio bursts, J. Geophys. Res. (in press).

Maxwell, A., and A. R. Thompson (1962), Spectral observations of solar radion bursts. II. Slow-drift bursts and coronal streamers, Ap. J. 135, 138.

Thompson, A. R. (1961), Spectral observations of solar radio bursts. I. Receiving equipment, Ap. J. 133, 643.

Thompson, A. R. (1961), Sweep frequency observations of meteor scatter burst, J. Atmospheric Terrest. Phys. 22, 161.

Thompson, A. R. (1962), Type IV (Continuum) bursts from the sun, Proceedings of the International Conference on Cosmic Rays and the Earth Storm, Phys. Soc. Japan 2, 198.

Thompson, A. R., and A. Maxwell (1962), Spectral observations of solar radio bursts. III. Continuum bursts, Ap. J. 156, 546 .

\section{Harvard College Observatory}

\section{Radio Astronomy Group and Space Radio Project, Cambridge, Mass.}

The major areas of research by the Radio Astronomy Group and the Space Radio Project at Harvard Observatory have been:

(1) A maser survey of the 21-cm emission of extragalactic nebulae;

(2) A search for the 21-cm emission of intergalactic hydrogen;

(3) A high latitude study of interstellar clouds;

(4) A study of atomic hydrogen over the north galactic pole;

(5) A continuum study of Venus and Jupiter;

(6) A calculation of the radio spectrum of the planet Earth, as viewed from space, particularly near $60 \mathrm{Gc} / \mathrm{s}$;

(7) An investigation of the planet Venus based on radar and radio astronomical research;

(8) A space radio telescope study of the planet Venus executed from the Mariner II planetary probe;

(9) An investigation of the radio spectrum near the Earth at frequencies between 1 and $10 \mathrm{Mc} / \mathrm{s}$.
Publications resulting from these research programs are listed below.

\section{Bibliography}

Cooper, B. F. C. (1961), Use of a Y-type circulator switch with a 21-cm maser radiometer, Rev. Sci. Instr. 32, 202-203.

Dieter, N. H. (1962), A search for HI in Centaurus A, A.J. 6\%, 222-223.

Neutral hydrogen in M33, A.J. 68, 217-221; Neutral hydrogen in IC342, A.J. 67, 313-316; Neutral hydrogen in M101, A.J. 67, 317-320; Neutral hydrogen in Nearby Sc Galaxies, A.J. 67, 270, (A).

A radio and optical investigation of extragalactic red shifts (with E. E. Epstein, A. E. Lilley, and M. S. Roberts), A.J. 67, 270-271, (A).

Radio red shifts of extragalactic nebulae (with E. E. Epstein, A. E. Lilley, and M. S. Roberts) URSI, Washington, D.C. (Apr. 30, 1962).

Epstein, E. E., Atomic hydrogen in galaxies, PhD Thesis, Harvard University (1962).

Neutral hydrogen in galaxies, URSI, Washington, D.C. (Apr. 30, 1962).

Atomic hydrogen in galaxies, A.J. 68, 271, (1962) (A). 
Goldstein, S. J., Spectral indices of 55 discrete sources, URSI, Washington, D.C. (May 1961).

Spectral indices of 60 discrete sources, A.J. 66, 285, (1961) (A).

Electronically-scanned radio telescopes (with I. M. Faigen), NEREM, Boston, Mass. (Nov. 1961).

Observations of sixty discrete sources at $1523 \mathrm{Mc}$, A.J. 67, 171, (1962) (A).

An attempt to observe 21-cm line emission from intergalactic hydrogen, A.J. 67, 577, (1962) (A).

Jelley, J. V. (1961), An operational ruby maser for observations at $21-\mathrm{cm}$ with a 60 -foot radio telescope (with B. F. C. Cooper), Rev. Sci. Instr. 32, 166-175.

Lilley, A. E. (1961), Radio properties of an orbiting scattering medium, A.J. 66, 116-118.

Low frequency cosmic radio emission (with G. R. Huguenin) Space Research II, Proceedings of the Second International Space Science Symposium, Florence, April 10-14, pp. 593-596.

The temperature of Venus, A.J. 66, 290.

Radio astronomy in the solar system, Publication No. 6/3, WESCON Conference, Pasadena, Calif. (Aug. 1961).

Fundamental requirements of radioastronomical measurements, NEREM Record, p. 54 (1961).

Millimeter-wave space radio telescopes, presented at XII International Astronautical Congress, Washington, D.C. (Oct. 1-7, 1961).

Space radio telescopes, IRE International Convention Record 10, pt. 8, 29-31 (1962).

Satellite measurements of cosmic and planetary radio noise, pp. 253-273, Space Age Astronomy (New York Academic Press, 1962).

Objectives of the Mariner Venus microwave radiometer experiment (with A. H. Barrett, J. Copeland, and D. E. Jones) Technical Report 32-156, Jet Propulsion Laboratory, Pasadena, Calif.

Some proposed measurements of atmospheric radiation at millimeter wavelengths (with M. L. Meeks), URSI, Washington, D.C. (Apr. 30, 1962).

Preliminary results of the Mariner II microwave radiometer experiment (with F. T. Barath, A. H. Barrett, J. Copeland, and D. E. Jones), Science (Mar. 8, 1963).

The microwave spectrum of oxygen in the earth's atmosphere (with M. L. Meeks), J. Geophys. Res. (in press).
Radio astronomical measurements pertinent to cosmology, Advances in Astronautical Science, Vol. VIII (Plenum Press; in press).

Contributions of masers to radio astronomical research (with E. B. Treacy), presented at the 3d Quantum Electronics Conference, Paris (Feb. 11, 1963).

Mariner II microwave observations of Venus (with A. H. Barrett), Sky and Telescope 25, No. 4 (1963).

Muhleman, D. O., Information on the surface, atmosphere, and rotation rate of Venus from radar observations, URSI, Washington, D.C. (Apr. 20, 1962).

Radar results as constraints on the models of Venus, A. J. 67, 277, (1962)(A).

The electrical characteristics of the atmosphere and surface of Venus from planetary observations, Icarus (in press).

Papagiannis, M. D., A $Z$-mode space radio program (unpublished) (with G. R. Huguenin).

Theory of the $Z$-mode propagation.

Roberts, M. S., Survey reports of 21-cm maser observations at Harvard, URSI, Washington, D.C. (May 1961).

21-cm maser observations of galaxies, A.J. 66, 294, (1961) (A)

Report of radio observations of galaxies made at Harvard, IAU Symposium No. 15 on Problems of Extragalactic Research, Santa Barbara, Calif. (Aug. 1961).

Report of the Harvard work on galaxies, presented to joint meeting of Commissions 28 and 40, IXth General Assembly, IAU (Aug. 1961).

The neutral hydrogen content of late-type spiral galaxies, A.J. 67, 437-446 (1962).

A Study of Neutral Hydrogen in IC 10, A.J. 6\%, 431$436,(1962)$.

Correlation of Jupiter decimeter radiation with solar activity, A.J. 67, 280, (1962)(A).

The relation of solar activity to Jupiter decimeter radiation, URSI, Washington, D.C. (Apr. 30, 1962).

The radiation belts of Jupiter (with G. R. Huguenin), 11th International Astrophysical Symposium, Liege, Belgium (July 9-11, 1962).

Sandler, S. S., Effective area of satellite-borne antennas for radio astronomy, submitted to Planetary and Space Sciences.

Antenna study for $Z$-mode space radio program (unpublished).

\section{Harvard College Observatory Radio Meteor Project, Cambridge, Mass.}

From September 1960 to November 1961 the Harvard Radio Meteor Project was operated with one transmitting station and three spaced receiving stations. Although the original design called for a six station system, the partial system was sufficient to determine the velocity, radiants, and orbits of individual meteors. The full six station system was completed with antennas of intermediate gain in November 1961 and a regular survey of meteor activity commenced on January 1, 1962. A $40 \mathrm{Mc} / \mathrm{s}$ transmitter was made available by the National Bureau of Standards at the site in Havana, Ill. During the first year of the survey the transmitter maintained an output of $2 \mathrm{Mw}$. During the first year of the survey the system operated down to a limiting magnitude of +11 . A phase comparator was designed and built for the determination of azimuth and height of the meteor. Heights were also determined approximately from the known azimuth of the antenna.
The IBM reduction program, originally prepared by L. Meeks, was substantially revised by R. B. Southworth. The Fresnel patterns at six stations are measured independently by two observers and the results intercompared by the 7090 machine. The mean values are used to determine the velocity, deceleration, electron line density, and radiant point of the meteor. In determining the velocity, corrections are applied for the effects of diffusion of the trail and greater precision has resulted in the velocity determinations. At the present time 1,500 meteors have been prepared in final form including derivation of orbital elements.

Confirmation was obtained of the anomalous characteristics of the orbits of radio meteors that have previously been reported. The average magnitude of meteors in the radio sample was +8 on the visual scale, some 5 magnitudes fainter than the meteors observed by Super-Schmidt cameras. The orbits were, in general, considerably smaller than 
the orbits of photographic meteors and there was an indication of a progressive change in which fainter meteors showed orbits with smaller eccentricity and smaller semimajor axis. The results confirmed the existence of the "toroidal group," meteor particles moving in almost circular orbits highly inclined to the plane of the solar system. This group is almost certainly a real component in the solar system and is not a result of observational selection, but its origin is at present difficult to ascertain. Two mechanisms have been considered for the production of the toroidal group. Firstly, it is thought that the particles may be considerably older than the average meteoroid and that secular perturbation by the planets has gradually increased the inclination of the orbits. Secondly, the possibility that the toroidal meteors were injected in the past by a large, high inclination comet has been given consideration.

The computed orbits have been intercompared to search for a similarity of elements. Using a criterion of orbit similarity that has been applied to the orbits of photographic meteors, a large proportion of the radio meteor orbits were found to belong to streams. Streams previously discovered by the photographic technique were confirmed and additional streams were discovered by means of the radio method.

Precise measurement of velocities at six spaced stations has yielded, for the first time, reliable measures of the deceleration of radio meteors. The rates of deceleration vary from 5 to $30 \mathrm{~km} / \mathrm{sec}^{2}$ and among the shower meteors, the first velocity observed for any one meteor is some 1 to $3 \mathrm{~km} / \mathrm{sec}$ below the no-atmosphere velocity. Although the decelerations of this size are predicted by the classical single-body theory, the height of occurrence of the meteor trails is lower than predicted by the classical theory.

From measures at six stations it has been possible, for the first time, to measure the ionization curve of the meteor and hence derive the mass of the meteoroid. From a knowledge of the mass and deceleration the density of the particles has been determined.
The average density is found to be $0.1 \mathrm{~g} / \mathrm{cm}^{3}$, which is comparable to the values of density found by the photographic method. Thus, it seems that the low density fragile structure of the meteoroid has been confirmed down to at least magnitude +8 .

\section{Bibliography}

Chilton, B. L. (1961), Analysis procedure, Research Report 10.

Chilton, B. L. (1961), Calibration program, Research Report 9.

Chilton, B. L. (1961), Comparison program, Research Report 8.

Chilton, B. L. (1961), Instructions for film analysis and film search, Research Report 2.

Chilton, B. L. (1961), Meteor reduction program data processing, Research Report 7 .

Final Report of CST 7067 (13 Dec. 1957 to 31 July 1960).

Final Report of CST 7282 (13 Dec. 1957 to 30 June 1961).

Hawkins, G. S. (1962), Radar determination of meteor orbits, Astron. J. 67, 241.

Hawkins, G. S. (1962), Radar determination of meteor orbits, Research Report 13.

Hawkins, G. S. (1960), D. M. Lewis, and M. L. Meeks, The time of transit of radiants in the sensitive sectors of an antenna, Research Report 1.

McDonough, W. H. (1961), Ground wave blank generator, Research Report 5.

MeDonough, W. H. (1961), Miscellaneous circuit diagrams, Research Report 6.

McDonough, W. H. (1961), Motor control unit, Research Report 4.

MeDonough, W. H. (1961), Video amplifier and gate unit, Research Report 3.

McLellan, J. W. (1961), Safety factor of transmitter radiation field, Research Report 11.

Southworth, R. B., Characteristics of faint radio meteors, URSI Commission V (Spring 1962).

Southworth, R. B. (1962), Deceleration of radio meteors, Astron. J. 67, 283.

Southworth, R. B., Theoretical Fresnel patterns of radio meteors, URSI Commission V (Fall 1962).

Southworth, R. B. (1962), Theoretical Fresnel patterns, Research Report 14.

Southworth, R. B., and J. J. DeSousa (1962), Harvard radio meteor project: The system, its operation, and its objective, Research Report 12 .

Whipple, F. L., and G. S. Hawkins (1956), The Harvard radio meteor project.

\section{University of Illinois, Urbana, Ill.}

The University of Illinois parabolic cylinder radio telescope was placed in operation in October 1962. The first research attempted was the mapping of the Cygnus $\mathrm{X}$ region at $611 \mathrm{Mc} / \mathrm{s}$. The resulting contour map was presented at the AAS meeting in West Virginia in December. The temperature of the full moon has been measured as $230^{\circ} \mathrm{K}$ at 611 $\mathrm{Mc} / \mathrm{s}$ with a probable error of about 10 percent. To calibrate the declination steering of the radio telescope, all sources stronger than $18 \times 10^{-26}$ Janskys (at $960 \mathrm{Mc} / \mathrm{s}$ ) have been observed at $611 \mathrm{Mc} / \mathrm{s}$. An improved feed system is under construction and will be placed in operation shortly, at which time the survey of faint extragalactic sources will begin.

A radio interferometer has been placed in operation or $73 \mathrm{Mc} / \mathrm{s}$ for the study of radio star scintillation. Two additional interferometers will be constructed, one in Mississippi and one in northern Michigan, for a long term study of the latitude distribution of scintillation.

\section{Bibliography}

MeVittie, G. C., (1960), A Radio Astronomy Project at the University of Illinois, IRE Trans. Military Electron. MIL-4, 14.

MeVittie, G. C., (1962) Fact and theory in cosmology (Byre and Spottiswoode, London, 1961) (Macmillan Co., New York).

MeVittie, G. C., (1962), Illinois' Vermillion River Observatory, Sky and Telescope $\mathbf{2 4}, 322$.

McVittie, G. C., (1962), Cosmology and the interpretation of astronomical data, Les Théoires Relativistes de la Gravitation, Centre National Recherche Scientifique, Paris 253.

Swenson, G. W., Jr., and Y. T. Lo (1961), The University of Illinois radio telescope, IRE Trans. Ant. Prop. AP-9, 9.

Schuster, D., C. T. Stelzreid, and G. S. Levy (May 1, 1961), The determination of noise temperatures of large antennas, JPL Technical Report No. 32-97.

Initial report for presentation at 1961 URSI Meeting, Washington, D.C.

Stelzried, C. T., Liquid-helium-cooled coaxial termination, Proceedings IRE (Correspondence), 49, p. 1224; July 1961 Cryogenic Load Report. 
Stelzried, C. T., D. Schuster, and T. Sato (Nov. 1961), An experimental 960 MC maser amplifier system applicable to space communications, JPL Technical Report No $32-179$.

External report on the first Goldstone 960 Me maser system and some radiometric tests.

Victor, W. K., and R. Stevens, Space research III, ed., W. Priester (North-Holland Publishing Co., Amsterdam) (in press).
Victor, W. K., and R. Stevens (June 1962), The 1961 JPL Venus radar experiment, IRE Trans. SET, SET-8, No. 2, $84-97$.

Presents a summary of the experiment including some temperature data.

Edited by W. K. Victor, R. Stevens, and S. W. Golumb (Aug. 1, 1961), Radar exploration of Venus, JPL Technical Report No. 32-132.

Includes reports on the maser, radiometer, polarization tests and radiometric tests.

\section{Jet Propulsion Laboratory, Pasadena, Calif.}

\section{Bibliography}

Levy, G. S., and D. Schuster (June 1962), Venusian and lunar radar depolarization experiments, Astron. J. (Reports on radiometric polarization tests as well as on planetary radar signal depolarization.)

Potter, P. D. (June 1962), The application of the Cassegrainian principle to ground antennas for space communication, IRE Trans. Space Electronics and Telemetry SET-8, No. 2, 154-158. (Reports on the performance of an extremely low noise temperature Cassegrain antenna.)

Potter, P. D. (June 22, 1962), Unique feed system improves space antennas, Electronics. (Description and design of an extremely low noise temperature Cassegrain antenna system.)

Sato, T., and C. T. Stelzried (June 1962), An operational 960 960 Mc maser system for deep-space tracking missions, IRE Trans. Space Electronics Telemetry SET-8, No. 2 , 164-170. (Report on the performance of an operational low noise temperature system.)

Schuster, D., C. T. Stelzried, and G. S. Levy (May 1962), The determination of noise temperatures of large antennas, IRE Trans. PGAP. (Reports research on low noise antenna feeds for large antennas, radiometric receiving and calibration equipment and methods of radiometric calibrations. Includes material not in reference 1.)

\section{Lincoln Laboratory}

\section{Massachusetts Institute of Technology, Lexington, Mass.}

Research since 1960 has been concerned with microwave studies of planetary atmospheres. The objective of this research is to investigate the microwave spectrum of planetary atmospheres, and the initial phase of research involves a theoretical investigation based on model atmospheres and laboratory measurements of the microwave spectra of atmospheric constituents. During the current period, detailed computations have been made to investigate the earth's atmosphere. The objectives of this research have been as follows:

1. Determination of the limitation of the earth's atmosphere to microwave astronomy.

2. Specification of equipment parameters and ob- servations to study the earth's atmosphere from the surface, from mountain tops, and from aircraft and balloons.

3. Development of concepts and specifications for sounding the thermal structure of the earth's atmosphere from radiometric satellites.

\section{Bibliography}

Meeks, M. L. (1961), Atmospheric emission and opacity at millimeter wavelengths due to oxygen, J. Geophys. Res. 66 3749 .

Meeks, M. L., and A. E. Lilley (1963), The microwave spectrum of the earth's atmosphere, J. Geophys. Res. (in press).

\section{University of Michigan, Ann Arbor, Mich.}

Since the last report of April 1960 a number of improvements and additions have been made to the 85 - $\mathrm{ft}$ radio telescope including new radiometers and fully digitized data recording. Several extended sources have been studied, the flux density of a few dozen nonthermal sources has been measured at $8000 \mathrm{Mc} / \mathrm{s}$, radio emission from Mercury was discovered, measurements of Venus, Mars, Jupiter, and Saturn are underway, occultations of radio sources by the moon at $800 \mathrm{Mc} / \mathrm{s}$ are also underway, an upper

*The present report covers only work on planetary atmospheres. Other research by this Laboratory is covered in separate reports to Commission II. limit to the radio flux density of the Nova of February 1963 has been set at $8000 \mathrm{Mc} / \mathrm{s}$ and at 800 $\mathrm{Mc} / \mathrm{s}$. The polarized component of six bright nonthermal radio sources has been measured at $8000 \mathrm{Mc} / \mathrm{s}$.

Solar burst spectra recordings using the 28 -ft radio telescope were discontinued in October 1961, after operating for over three years, because of equipment wear and reduced solar activity. Plans are now underway for obtaining fast recordings of fast-drift solar bursts at several fixed frequencies from 38 $\mathrm{Mc} / \mathrm{s}$ to $300 \mathrm{Mc} / \mathrm{s}$.

The space radio astronomy effort has grown appreciably since the last report. A rocket experiment 
was completed and we are participating in two scientific satellite programs: the eccentric orbit geophysical observatory satellite (EGO) with a solar burst spectrometer, and the polar orbit geophysical observatory satellite (POGO) with a $2.5 \mathrm{Mc} / \mathrm{s}$ cosmic noise survey.

\section{5-Ft Radio Telescope}

Data system: Angular transducers with a peak error of 5 secs of arc were mounted on the antenna to determine the angular position of the polar and declination axes. The output of the axis transducers, sidereal time, and the output of the radiometers are digitized. This digital information and manually inserted parameter data are recorded on printed paper, for visual presentation, and on punched cards for processing in an IBM 7090 computer.

Radiometers: Traveling-wave tube receiver at $8000 \mathrm{Mc} / \mathrm{s}$ : Several major modifications have been made to improve the stability and reliability of the receiver. The most significant improvement has been the addition of a tunnel diode rf amplifier, ahead of the traveling-wave tubes, mounted at the apex of the antenna. The overall system temperature is now approximately $1000{ }^{\circ} \mathrm{K}$ at a band width of $1000 \mathrm{Mc} / \mathrm{s}$.

Dicke radiometer at $1.8 \mathrm{~cm}$ wavelength: Increasing the bandwidth to $20 \mathrm{Mc} / \mathrm{s}$ has been the most significant improvement. This radiometer has been used in mapping the sun, moon, and other strong radio sources.

Maser radiometer at $8700 \mathrm{Mc} / \mathrm{s}$ : The maser radiometer was removed from the antenna during the summer of 1962 . It is presently being modified to improve its reliability and noise temperature.

Radiometer at $800 \mathrm{Mc} / \mathrm{s}$ : A Dicke radiometer has been installed on the antenna. The bandwidth is $5 \mathrm{Mc} / \mathrm{s}$ and the overall system noise temperature is $600{ }^{\circ} \mathrm{K}$. A number of sources have been observed and it is planned to observe moon occultations of radio sources.

Maser radiometer at $10,000 \mathrm{Mc} / \mathrm{s}$ : A multicavity ruby maser radiometer is being designed and built by the University of Michigan, Willow Run Laboratories and should be completed this year.

The plane polarized component of several radio sources measured at $8000 \mathrm{Mc} / \mathrm{s}$ : During 1962 several radio sources were observed with the broadband TW'T radiometer covering the band from 7500 to $8500 \mathrm{Mc} / \mathrm{s}$ with a rotating feed horn on the $85-\mathrm{ft}$ radio telescope. The radiometer noise fluctuations have an rms value of $0.03{ }^{\circ} \mathrm{K}$ with a 10 sec integration.

The feed horn was specially designed to have wellmatched $E$ - and $H$-plane radiation patterns over the band. The circular antenna beamwidth was about $0.1 \mathrm{deg}$. The horn was rotated at a uniform rate of 0.5 rotation per sidereal minute while the antenna beam tracked the radio source. The output was compared to similar off-source measurements. On thermal radio sources, such as the Orion nebula, the radiometer output showed no detectable correlation with the position angle of the feed horn. On the nonthermal sources Taurus A (Crab nebula) and Cygnus A, the phase and amplitude of the sine-wave variation of radiometer output gives position angle and percent plane-polarized components consistent with values obtained by Mayer and his coworkers on these sources at nearly the same frequency.

The plane polarized component has also been observed in several additional sources: Centaurus A, 3C 273, and Tycho's supernova of 1572 .

Flux density of nonthermal radio sources at 8000 $\mathrm{Mc} / \mathrm{s}$ : Preliminary flux density measurements at $8000 \mathrm{Mc} / \mathrm{s}$ have been made on 20 nonthermal smalldiameter radio sources. Only the north-south plane of polarization component was measured. The majority of these sources have not been previously measured at $8000 \mathrm{Mc} / \mathrm{s}$. Lower frequency measurements of these same sources indicate that five of them, including Cygnus $\mathrm{A}$, have spectra which curve downward at high frequencies on a $\log$ flux density versus log frequency plot. This curvature is confirmed by these measurements. In addition some five other sources appear to show curvature based only on $8000 \mathrm{Mc} / \mathrm{s}$ measurements. This work is being extended, and it is planned that a list of flux measurements for about 40 radio sources will soon be available.

Measurement of microwave radiation from the planet Mercury: The microwave emission from the planet Mercury has been measured relative to the flux density of three radio sources at wavelengths of 3.45 and $3.75 \mathrm{~cm}$, using the $85-\mathrm{ft}$ reflector with two different radiometers. The measured mean antenna temperature is $0.05{ }^{\circ} \mathrm{K}$. From this value a mean equivalent blackbody disk temperature of about $400^{\circ} \mathrm{K}$ is derived. A subsolar point temperature of the planet of $1100 \pm 300{ }^{\circ} \mathrm{K}$ (est.m.e.) at mean solar distance is derived if it is assumed that the temperature distribution of the sunlit surface of Mercury varies as the one-quarter power of $\cos \theta$, where $\theta$ is the angle of incidence of solar radiation, and that the temperature of the dark hemisphere is zero. A lower subsolar temperature is obtained if radioactive heating and a lunar-type insulating dust layer on the surface are assumed, since the dark hemisphere will then contribute to the mean disk temperature. The effect of orbital libration will also modify the deduced subsolar temperature.

Observations of radio sources at $1.8 \mathrm{~cm}$ wavelength: Observations of the microwave radiation at $1.8 \mathrm{~cm}$ wavelength $(16.7 \mathrm{Gc} / \mathrm{s})$ from the sources Cas A, Tau A, Orion nebula, M17, and Cyg A were obtained. Flux density ratios to Cas A and angular source sizes, assuming a Gaussian shape, were derived. Within the uncertainties of the observations, the sources appear circularly symmetric, with the exception of $\mathrm{Cyg} \mathrm{A}$, which has an east-west width of $2.6^{\prime} \pm 0.7^{\prime}$ and a north-south width $<$ $1.5^{\prime}$.

The central component of the galactic center source, Sagittarius A: From an analysis of the position determinations at centimeter wavelengths of 
the bright central component of Sagittarius A made with $25-\mathrm{m}$ paraboloids, the right ascension of the galactic center was found to be $17^{\mathrm{h}} 42^{\mathrm{m}} 24.2^{\mathrm{s}} \pm 1^{\mathrm{s}}$ (pe), epoch 1950. The width of this central component to half-intensity points is about $5.5 \mathrm{~min}$ of arc, which corresponds to a linear size of about 16 $\mathrm{pc}$ at an assumed distance of $10 \mathrm{kpc}$, and its flux density at $8000 \mathrm{Mc} / \mathrm{s}$ is found to be $(1.3 \pm 0.2 \mathrm{pe}) \times$ $10^{-24} \mathrm{~W} \mathrm{~m}^{-2}(\mathrm{c} / \mathrm{s})^{-1}$.

An investigation of the supernova remnant IC 443 at $8000 \mathrm{Mc} / \mathrm{s}$ : Using the $85-\mathrm{ft}$ radio telescope and the $8000 \mathrm{Mc} / \mathrm{s}$ traveling-wave tube radiometer, a radio map of the radio source IC 443 in Gemini was obtained. Taurus A was used as a calibration source to obtain a flux density of $8.5 \times 10^{-25} \mathrm{w} \mathrm{m}^{-2}(\mathrm{c} / \mathrm{s})^{-1}$. The peak intensity at $8000 \mathrm{Mc} / \mathrm{s}$ is located at R.A. (1950) $16^{\mathrm{h}} 14^{\mathrm{m}} 08^{\mathrm{s}}$ and Dec. (1950) N $22^{\circ} 42^{\prime}$.

Comparison of this flux density with those reported at lower frequencies gave a power-law spectrum with slope or spectral index of $0.39 \pm 0.03$, with no evidence of deviation from a simple powerlaw spectrum.

\section{Solar Radio Astronomy}

The variation of the correlation of E-region ionization with solar radio emission at different frequencies was studied. A low correlation coefficient at wavelengths greater than $30 \mathrm{~cm}$ indicates the majority of soft solar x rays responsible for $E$-layer ionization originate in the solar atmosphere below the source of the $30 \mathrm{~cm}$ radio radiation.

The Michigan sweep-frequency records in the 100 to $500 \mathrm{Mc} / \mathrm{s}$ and 2000 to $4000 \mathrm{Mc} / \mathrm{s}$ ranges were compared with the Convair-Caltech 500 to $950 \mathrm{Mc} / \mathrm{s}$ sweep-frequency observations. The most important result of the comparison was the finding that fast drift bursts in the 500 to $950 \mathrm{Mc} / \mathrm{s}$ range do not generally extend into the 100 to $500 \mathrm{Mc} / \mathrm{s}$ range.

Interferometric records of Type IV bursts at 340 and $87 \mathrm{Mc} / \mathrm{s}$ obtained at the Carnegie Department of Terrestrial Magnetism were investigated. Two phases of Type IV are distinguished according to their frequency; no motion occurs for bursts detected at $340 \mathrm{Mc} / \mathrm{s}$ while sources at 87 may show large movement.

Solar $\mathrm{x}$ rays were found closely associated with centimeter-wave solar bursts and only weakly correlated with Type III bursts in spite of the inferred high energies of Type III electrons. Centimeterwave bursts associated with Type III bursts do not show a sharp low frequency cutoff probably because of an additional component of synchrotron radiation added to the thermal component.

An analysis of Type III bursts and related flare activity in 1959 was made using times when the Sacramento Peak and Lockhead flare patrols were simultaneously operating. Making an extrapolation to "zero" flare area, only 75 percent of the groups of Type III bursts can be associated with flare activity. Bursts clearly resulting from flares appear most frequently at the flash phase of the flare. An interesting relationship between noise storms and Type
III bursts was found; flares occurring in regions on the solar disk associated with strong noise storm activity have approximately twice the probability of producing Type III bursts than do flares occurring far from such regions. The frequency at which the Type III bursts first appear is also related to the frequency of the simultaneous noise storm. The duration of Type III bursts at $25 \mathrm{Mc} / \mathrm{s}$ is found to be $5 \mathrm{sec}$; if the duration is largely determined by the collision frequency in the corona, a temperature of 2.7 million degrees is indicated.

A theoretical model of Type III bursts was developed involving the excitation of plasma oscillations by a coherent traveling-wave tube type interaction and coupling to electromagnetic waves by Rayleigh scattering. A turnover in the spectrum of the bursts is predicted near $50 \mathrm{Mc} / \mathrm{s}$. It is suggested the bursts first become visible at frequencies corresponding to the position of the steep temperature gradient in the chromosphere-corona transition region.

The occurrence of Type IV radiation from flares covering sunspot umbrae was investigated. The fraction of the total umbral area of a spot group covered by a flare is found related to the intensity of the associated $2800 \mathrm{Mc} / \mathrm{s}$ burst and the occurrence of a meter- $\lambda$ Type IV radiation.

Flares consisting of slowly expanding double filaments were studied. The deceleration of the expansional motion is greatest for flares occurring near large sunspot groups, and appears related to the magnetic pressure experienced by the flare filament. Expanding flares may have a slightly greater probability of producing Type IV bursts than flares of the same area covering the same fraction of sunspot umbrae.

\section{Theoretical Studies}

The possibility of detecting radiofrequency fine structure transitions of the metastable $\mathrm{H}_{2}$ molecule in H I regions (neutral hydrogen galactic clouds) was investigated. Using for the number of absorbing molecules along the line of sight an estimate based upon the suggested identification of the $4430 \AA$ line with the $\mathrm{H}_{2}$ molecule, the optical depth of the line at $5898 \mathrm{Mc} / \mathrm{s}$ is found to be less than $10^{-7}$ the optic depth of the $21 \mathrm{~cm}$ line.

\section{Space Radio Astronomy}

Rocket probe results: On 22 September 1962 at 01:46 am, EST, a Journeyman rocket was launched from Wallops Island, Va., with a radio astronomy payload of $144 \mathrm{lb}$. Maximum altitude attained was 1700 $\mathrm{km}$, good telemetry reception being obtained throughout the flight. The experiment payload consisted of three radiometers, designed to measure cosmic radio intensity, operating simultaneously at $0.75,1.225$, and $2.0 \mathrm{Mc} / \mathrm{s}$ connected to a common electric dipole antenna $12.5 \mathrm{~m}$ overall length; this is only $0.03 \lambda$ long at $0.75 \mathrm{Mc} / \mathrm{s}$. A solid-state noise diode for receiver gain calibration and a circuit designed to measure antenna capacitance operated satisfactorily with a 12 -sec sampling period throughout the flight. 
The in-flight antenna capacitance at $1.2 \mathrm{Mc} / \mathrm{s}$ measured beneath the ionosphere agreed with a preflight ground calibration. The measured apogee value of antenna capacitance at $1.2 \mathrm{Mc} / \mathrm{s}$ was about 15 percent below the free-space value due to the presence of residual ionospheric plasma. This small reduction requires a simple correction to the measured cosmic intensity at this frequency to obtain the free space value. Only a very small correction for ambient plasma is required for the $2.0 \mathrm{Mc} / \mathrm{s}$ measured intensity. The $0.75 \mathrm{Mc} / \mathrm{s}$ measurement was seriously affected by ambient plasma and the local geomagnetic field. Further study is required to deduce even an approximate cosmic intensity to this frequency.

Preliminary analysis indicates that down to 2 $\mathrm{Mc} / \mathrm{s}$ there is no falloff from a power-law spectrum with index 0.5 , based on the best higher frequency values reported.

Instrumentation: A receiver sweeping over the range 2 to $4 \mathrm{Mc} / \mathrm{s}$ every $2 \mathrm{sec}$ has been developed for the first EGO satellite, and prototypes delivered to NASA. Using a $30-\mathrm{ft}$ monopole operating against the spacecraft as an unbalanced dipole antenna, it is hoped to observe solar and Jovian activity in this frequency range.

A receiving system is under development for the first POGO satellite to carry out a survey of cosmic noise at $2.5 \mathrm{Mc} / \mathrm{s}$ using the theoretically predicted ionospheric focusing to obtain directivity. The antenna will be a 60 -ft monopole operating against the spacecraft body. The antenna impedance is monitored continuously to permit correction for effects of the local ionospheric plasma.

Planetary ionospheres: Theoretical work was done on models of the ionosphere and lower exosphere to assist in the design and interpretation of data from space radio astronomy experiments. The theoretical ion distributions for a three-component isothermal exosphere were extended to a multicomponent nonisothermal atmosphere, and rapid means were developed for constructing such models, based on assumed abundances of the principal ionic constituents. Diurnal variations were included in models of the terrestrial exosphere, based on the assumption that the total number of $\mathrm{He}^{+}$and $\mathrm{H}^{+}$ions under terrestrial control could not vary significantly over a period of a day or less. These results appeared to be in agreement with some data obtained by ionprobe measurements of true ion or electron densities at a few crucial altitudes. Interpretation of theoretical results indicates that in addition to the long-term temperature dependence of the abundances of $\mathrm{He}^{+}$ and $\mathrm{H}^{+}$ions, related to their rate of escape from the earth as a function of temperature, there is also a strong diurnal temperature dependence of their peak number densities, due primarily to subsidence from day to night. The results also indicate that temperatures deduced from topside ionosphere scale heights may at times be in error, due to lack of knowledge of the true mean molecular weight in this region.

Lunar ionosphere: A physical, mathematical, and numerical analysis was carried out of a process (originally investigated more crudely by Herring and
Lieht) for possible formation of a lunar ionosphere via a charge-excharge process involving the protons of the solar wind. A typical result with a flux of $8 \times 10^{9}$ protons $\mathrm{cm}^{-2} \mathrm{sec}^{-11}$ at $700^{\circ} \mathrm{K}$ gives a singlelayer ionosphere with a minimum electron density of roughly $350 \mathrm{~cm}^{-3}$ at 0.6 lunar radii above the subsolar point. There is only slow variation with angle of the radial location and magnitude of the maximum of the layer until about $60^{\circ}$ off this direction; then rapid decreases in both quantities begin.

By-products of this investigation are analytic formulas for the gas velocity ahead of a blunt vehicle in the early stages of entry into a planetary atmosphere.

Solar bursts: In connection with the 2 to $4 \mathrm{Mc} / \mathrm{s}$ sweep receiver for the EGO satellite, theoretical studies were made of the nature of solar activity at low frequencies.

Antenna studies: A number of aspects of the behavior of an antenna in a plasma have been investigated. Studies have been made of the effect on radiation resistance and capacitance of a short electric dipole of anisotropic dielectric behavior due to the presence of a static magnetic field, and of the loading of such a dipole due to plasma waves. These studies are important for the interpretation of data obtained from radio astronomy observations from space vehicles.

\section{Bibliography}

Bair, M. E. (1961), J. J. Cook, L. G. Cross, and C. B. Arnold, Recent developments and observations with a ruby maser radiometer, IRE Trans. Ant. Prop. AP-9, 43.

Barrett, A. H. (1961), Microwave absorption and emission in the atmosphere of Venus, Ap. J. 133, 281.

Barrett, A. H. (1961), Observations of radio sources at 1.8 cm wavelength, Ap. J. 134, 945.

Casey, D. W., II, and J. W. Kuiper (1961), A 2-4 kMc sweep-frequency receiver, IRE Trans. Ant. Prop. AP-9, 36.

de Jager, C., and M. R. Kundu (1962), A note on bursts on radio emission and high energy $(<20 \mathrm{kev}) \mathrm{x}$ rays from solar flares, Cospar III Symposium Proceedings.

Haddock, F. T. (1961), Radio astronomy below $10 \mathrm{Mc} / \mathrm{s}$, Proceedings of the Space Age Symposium, 274.

Haddock, F. T. (1962), Thermal radio emissions from celestial bodies, Physical Sciences: Some recent advances in France and the United States, H. P. Kallmann, S. A. Korff, and S. G. Roth, editors (New York University Press).

Haddock, F. T., and R. W. Hobbs (Mar. 1963), The plane polarized component of several radio sources measured at $8000 \mathrm{Mc} / \mathrm{s}$, Astron. J.

Haddock, F. T., H. F. Schulte, and D. Walsh (Mar. 1963), Cosmic radio intensities at 1.2 and $2.0 \mathrm{Mc} / \mathrm{s}$ measured at an altitude of 1700 kilometers, Astron. J.

Howard, W. E., III (1961), Effects of antenna scan rate and radiometer time constant on receiver output, Astron. J. 66, 521 .

Howard, W. E., III, A. G. Barrett, and F. T. Haddock (1962), Measurement of microwave radiation from the planet Mercury, Ap. J. 136, 995.

Howard, W. E., III, and Helene R. Dickel (1963), An investigation of the supernova remnant IC 443 at $8000 \mathrm{Mc} / \mathrm{s}$, Proceedings of the Astronomical Society of the Pacific.

Howard, W. E., III, H. J. Rood, and P. B. Boyce (1962), The central component of the galactic center source, Sagittarius A, Ap. J. 136, 133 . 
Kundu, M. R. (1962), Association of centimeter-wave bursts with different spectral types of meter wave bursts of solar radio emission, Am. Geophys. Union 67, 2695.

Kundu, M. R. (1961), Bursts of centimeter-wave emission and the region of origin of $\mathrm{x}$ rays from solar flares, J. Geophys. Res. 66, 4308.

Kundu, M. R. (1962), Some relations between centimeterwave radio bursts and solar cosmic rays and $\mathrm{x}$ rays, J. Phys. Soc. Japan 1\%, Supplement A II, 259.

Kundu, M. R. (1961), Some studies on the occurrence of Type IV solar bursts of continuum radiation, Ap. J. 134, 96.

Kundu, M. R. (1962), The nature of Type IV solar radio bursts, J. Phys. Soc. Japan 17, Supplement A II, 215.

Kundu, M. R. (1960), Solar radio emission on centimeter waves and ionization of the $E$ layer of the ionosphere, J. Geophys. Res. 65, 3903.

Kundu, M. R., and J. W. Firor (1961), Interferometric studies of Type IV solar bursts of continuum radiation on 340 and $87 \mathrm{Mc} / \mathrm{s}$, Ap. J. 134, 389.

Kundu, M. R., and F. T. Haddock (1961), Centimeter-rvave solar bursts and associated effects, IRE Trans. Ant. Prop. AP-9, 82.

Kundu, M. R., J. A. Roberts, C. L. Spencer, and J. W. Kuiper (1961), A comparison of the dynamic spectra of solar radio bursts in the decimeter and meter wavelength ranges, Ap. J. 133, 255.

Kundu, M. R., and S. F. Smerd (1962), A note on Type IV emission, Information Bulletin of the European Solar Radio Observatory.

Kundu, M. R., and C. L. Spencer (to be published), Spectral characteristics of continuum radiation in the 500-1000 $\mathrm{Mc} / \mathrm{s}$ range, Ap. J.

Malville, J. M. (1962), The association of Type III bursts and solar flare, Ap. J. 351, 834.

Malville, J. M. (1962), Characteristics of Type III bursts, Ap. J. 136, 266.

Malville, J. M. (1962), Characteristies of Type III bursts, Astron. J. 67, 276.

Malville, J. M., The expansion of flare filaments, Proceedings of the Astronomical Society of the Pacific (in press).

Malville, J. M. (1962), Spectrum of coherent electron waves in the solar corona, Astron. J. 6\%, 580.

Malville, J. M., and G. E. Moreton (1961), The trajectories of chromospheric disc sources, Nature.

Malville, J. M., and S. F. Smith (1962), Association of Type IV radio bursts with flares covering sunspot umbrae, Proceedings of the Astronomical Society of the Pacific $\mathbf{7 4}, 406$.

Malville, J. M., and S. F. Smith, Type IV radiation from flares covering sunspots, J. Geophys. Res. (in press).

Seling, T. V. (1962), An investigation of a feedback control system for stabilization of microwave radiometers, IRE Trans. on Microwave Theory Tech. MIT-10, 209.

Simon, P. (1962), Meter wave emissive regions and Type III bursts, Ann. Astrophys. 25, 12.

Weil, H. (1963), Flow field in hypersonic re-entry, ARS Journal (in press).

Weil, H., and M. L. Barasch (1962), Model of the lunar ionosphere, Astron. J. 67, 1304.

Weil, H., and M. L. Barasch (1963), A theoretical lunar ionosphere, Icarus (in press).

\section{National Aeronautics and Space Agency, Goddard Space Flight Center, Greenbelt, Md.}

Solar studies. $136 \mathrm{Mc} / \mathrm{s}$ radiation from the sun has been monitored by the National Aeronautics and Space Administration Minitrack System for the past year and a half. Positions of the radio emission centers have been determined for both quiet and active periods. These are presently being compared with flare times and positions for possible correlations.

Low frequency galactic radiation. On September 22, 1962, the Goddard Space Flight Center and the University of Michigan launched a low frequency radio noise probe on an ARGO D-8 vehicle from Wallops Island, Va. The University of Michigan group under Professor F. T. Haddock designed the payload to measure radio frequency radiation from the galaxy at 750,1225 , and $2000 \mathrm{kc} / \mathrm{s}$ with a $12.5-\mathrm{m}$ dipole antenna. The probe reached a peak apogee of $1700 \mathrm{~km}$, and galactic radiation was measured at all three frequencies. In addition, the antenna capacitance was measured throughout the flight in order to measure the local electron densities. The 2000 and $1225 \mathrm{kc} / \mathrm{s}$ observations required only small corrections for the ionosphere, but the $750 \mathrm{kc} / \mathrm{s}$ measurements require extensive analysis before the cosmic intensity at this frequency can be deduced. Preliminary indications are that the spectrum of cosmic flux is still a straight line curve down to $1225 \mathrm{kc} / \mathrm{s}$.

This probe was the first phase of a program aimed at low-frequency observations from scientific earth satellites.

Radio star scintillations. A new 85-ft parabolic antenna facility was constructed in Fairbanks,
Alaska, in the summer of 1962 by the Goddard Space Flight Center. The facility was designed primarily for data acquisition from scientific earth satellites, but the first use of the antenna has been a study of radio star scintillations caused by the auroral ionosphere. This work is being conducted for Goddard by the Geophysical Institute of the University of Alaska. $136 \mathrm{Mc} / \mathrm{s}$ and $1700 \mathrm{Mc} / \mathrm{s}$ are the primary frequencies. In addition to the 85- $\mathrm{ft}$ antenna, 136 $\mathrm{Mc} / \mathrm{s}$ observations are being made with Goddard's 20-db yagi antenna at the Fairbanks Minitrack Station and with the Geophysical Institute's interferometers at 68,223 , and $456 \mathrm{Mc} / \mathrm{s}$. Radio star observations plus measurements of satellite signals during auroral activity have shown that multiple scattering in the auroral ionosphere is responsible for the scintillation phenomenon.

\section{Bibliography}

Fremouw, E., J. Hook, and L. Owren (1962), Aberrations of radio signals traversing the auroral ionosphere, Geophysical Institute Progress Reports 1-13 for Goddard Space Flight, Center Contract NAS 5-1413.

Habib, E. J., J. H. Berbert, and D. W. Harris, Sun tracking by the Minitrack Network Stations, NASA Technical Note D-1121.

Haddock, F. T., H. F. Schulte, and D. Walsh, Cosmic radio intensities at 1.2 and $2.0 \mathrm{Mc} / \mathrm{s}$ measured at an altitude of 1700 kilometers, American Astronomical Society Meeting (27XII1962)

Owren, L. (1962), Multiple scattering in the auroral ionosphere, Proceedings of the Institute of Physies and Physical Society Conference on the Ionosphere. 


\section{National Bureau of Standards, Boulder, Colo.}

In response to the request for material for the URSI National Committee report, we have very little of strictly astronomical interest to submit. Most of our observations of radio-astronomical sources are primarily for geophysical purposes. Although there are no published results, Dr. Bowles has made recent observation of radar echoes from Venus.
Daily observations of Venus were carried out, from November 28 through December 7, 1962, using the radar at Jicamarca, Peru. Pulses of 0.5 and 3 msec duration were used at a frequency of $49.92 \mathrm{Mc} / \mathrm{s}$. The echo was received in bursts of 5 to $15 \mathrm{sec}$, with signal-to-noise ratios as high as $3: 1$. The Doppler spread of the received signal was of the order of $\pm 1 \mathrm{c} / \mathrm{s}$. Complete reduction and interpretation of these observations are in progress.

\section{National Center for Atmospheric Research High Altitude Observatory, Boulder, Colo.}

The work since the London General Assembly has concentrated into three areas of low-frequency radio astronomy: (1) Solar decametric emission; (2) Jupiter decametric emission; (3) ionospheric scintillation and absorption. Equipment used in these studies includes at Boulder fixed-frequency interferometers at 36,18 , and $8 \mathrm{Mc} / \mathrm{s}$, the latter on a North-South baseline, and a swept-frequency interferometer in the range 7.6 to $41 \mathrm{Mc} / \mathrm{s}$. In addition, the observatory coordinates observations made with $18 \mathrm{Mc} / \mathrm{s}$ total power radiometers at Lake Angelus, Mich., Honolulu, Bagnio (near Manila in the Philippines), and Rome, Italy.

The ionospheric studies include a discussion of low-frequency absorption at Hawaii [Steiger and Warwick, 1961], and of synchrotron emission following the 9 July 1962 high-altitude atomic explosion, the "Starfish" shot, work still in preparation. Observations of unusual interference from manmade sources were presented [Warwick, 1963] with observations and discussion of natural terrestrial deca. metric sources. Scintillations observed with the spectrograph were discussed by Warwick [1963a]; the emphasis was that these phenomena are broadband, covering 2:1 or more in frequency, and often are caused by wave trains in the high ionosphere. Data on scintillations of Cassiopeia A have been obtained nightly and therefore include, as well as scintillations, observations of gross ionospheric refraction; analysis is continuing. 'The data on solar bursts and sudden cosmic noise absorptions from the $18 \mathrm{Mc} / \mathrm{s}$ radiometers are reported monthly in the CRPL F-Series, Part B.

During the day, the Boulder spectrograph tracks the sun. Since July 1959 this equipment has registered most of the important low-frequency solar emission events available at our longitude. These have been scaled and reported, since March 1961, in CRPL F-Series, Part B. Continuation of these scalings back to the first operation of the equipment is underway, and will appear as a special Observatory report. Analysis of the positions of many of the important events is in progress, with reductions under the direction of Adelle Wightman, essentially complete for the following:
20 July 1961, 6 September 1961, 10 September 1961, 28 September 1961, 22 April 1962

J. M. Malville finished his dissertation to the University of Colorado during the report period (June 1961). Using flare optical and radio observations from Boulder, Sacramento Peak, Fort Davis, and Lockheed, he discussed statistical relations between optical and radio phenomena, as well as a detailed physical mechanism of the two-stream instability type for generation of Type III bursts. This work has been partially published (Malville, 1962a, b). Lee and Warwick (1962) submitted a description of the Boulder spectrograph for the U.S. Report on radio astronomical techniques to appear in conjunction with the Australian group in the Australian Institute of Electrical Engineers. Included were dynamic spectra of a Type III harmonic burst at $8 \mathrm{Mc} / \mathrm{s}$, and of Jupiter's decametric emission.

Jupiter's decametric emission occupied a considerable fraction of the observing program with the spectrograph during the report period. 'The second generation of theory based on the spectrograph observations has now appeared [Warwick, 1963 b, c, d]. Descriptions of this work in early versions appeared in 1960 and 1961 [Warwick, 1960, 1961 a, b]. Data from 1962 are scaled in preliminary fashion but are not yet fully incorporated into the full data on which the theory is based. 1962 and 1963 data will be incorporated in a report to be prepared for Annual Review of Astronomy [1963e]. The main emphasis of these results is on the observational fact that Jupiter's dynamic spectrum is different from one longitude range to another, but closely repeatable within a given longitude range. As was emphasized previously [Warwick, 1960, 1961b] the dynamic spectra appeared to us inconsistent with the plasma oscillation theory of these bursts that had been the only theory developed to explain them before our observations. Since the frequency of emission, although variable from longitude to longitude, was fixed to a surprising extent at a given longitude, we felt that the primary generation of the emission was at the gyrofrequency, e.g., closely tied to the local, stable magnetic field in Jupiter's atmosphere. Other workers [Barrow, 1960] had concluded 
on emission at or near the gyrofrequency; however, they had postulated initial generation of the emission over a wide bandwidth. Propagation effects then permitted (so these early theories continued) escape of only one polarization mode, and within a narrow frequency range. Our theory, on the other hand, dealt with a narrowband mechanism for generation of the waves, in a Cerenkov effect.

Another novelty of the Boulder theory consisted in its disregard for the apparent burst structure of the decametric emission. Our data indicated a strong connection between the character (e.g., burstiness) of the emission and the character of ionospheric radio star scintillation observed simultaneously [Warwick, 1963b]. Also, we found position shifts of the emission during "bursts" on some occasions. The conclusion was that ionospheric scintillations, albeit of shorter duration and perhaps greater amplitude than exhibited by radio stars, were responsible for the bursty character. These effects could be related to the small size of Jupiter's decametric emission source. If one order of magnitude smaller source is required to change the scintil- lation durations by the observed order of magnitude, then the source at Jupiter must be smaller than a typical radio star (Cygnus $\left.\mathrm{A} \sim 1^{\prime}\right)$, e.g., perhaps 5 sec of arc. This is consistent with Jupiter's decametric source size as inferred from the theory.

\section{Bibliography}

Barrow, C. H. (1960), Nature 188, 924.

Lee, R. H., and J. W. Warwick (1962), (to be published).

Malville, J. M. (1962), Ap. J. 136, 266.

Malville, J. M. (1962), Ap. J. 135, 834

Steiger, S. R., and J. W. Warwick (1961), J. Geophys. Res. $\mathbf{6 6}$, p. 57.

Warwick, J. W. (1960), Science 132, 1250.

Warwick, J. W. (1961), Arkiv for Geofysik 3, 497.

Warwick, J. W. (1961), Annals of the New York Academy of Sciences 95, 39.

Warwick, J. W. (1963), Annual Review of Astronomy and Astrophysics 2 .

Warwick, J. W. (1963), Ap. J, 13\%, No. 1.

Warwick, J. W. (1963), Ap. J. 137, No. 3.

Warwick, J. W. (1963), Nature (in press).

Warwick, J. W. (1963a), Astron. J. 68.

Warwick, J. W. (1963), Radio astronomical and satellite studies of the atmosphere, Corfu Conference, pp. 400-429.

\section{National Radio Astronomy Observatory, Greenbank, W. Va.}

During the period covered by this report (September 1960 to February 1963) work at the NRAO has been primarily in the areas of planets, galactic and extragalactic nonthermal sources, and $\mathrm{H}$ II regions. The principal observing instrument in use has been the 85-ft Tatel telescope. It has been used for various programs at wavelengths of $3.75,10,21,40$, and $68 \mathrm{~cm}$. References to published results of work by-visitors and staff are given in the bibliography.

In March 1962 a 40-ft diam transit telescope was put into operation to investigate possible long term variations in the intensity of radiation from certain sources. Operation of the telescope and receivers is fully automatic. Observations of Cas A and several other sources are made daily at frequencies of $750 \mathrm{Mc} / \mathrm{s}$ and $1400 \mathrm{Mc} / \mathrm{s}$. This program will continue for several years.

The 300-ft transit telescope was put into operation in September 1962. Built under the direction of J. W. Findlay, it operates to $21 \mathrm{~cm}$ wavelength, where its beamwidth is $10 \mathrm{~min}$ of arc. It is in use by visitors and staff members on programs of discrete sources, background emission, galaxies, supernova remnants, H II regions, galactic and extragalactic $21 \mathrm{~cm}$ line, and planets.

\section{Bibliography}

Drake, F. D. (1960), The position determination program of the National Radio Astronomy Observatory, Publ. Astron. Soc. Pacific 72, 494.

Drake, F. D. (1961), Bright sources at 3.75, Proceedings URSI XIII General Assembly, 452.

Drake, F. D. (1961), Project Ozma, Physics Today 14, 40.

Drake, F. D. (1961), Radio emission from the planets, Physics Today 14, 30 .
Drake, F. D. (1962), $10 \mathrm{Cm}$ observations of Venus in 1961 Publications of the NRAO 1, 165 .

Drake, F. D. (1962), $10 \mathrm{Cm}$ observations of Venus near superior conjunction, Nature 195, 895 .

Drake, F. D. (1962), Microwave spectrum of Saturn, Nature 195, 893.

Drake, F. D. (1962), Project Ozma, Yearbook of McGraw Hill, Encyclopedia of Science and Technology.

Field, G. B. (1962), Absorption by intergalactic hydrogen, Ap. J. 135, 684 .

Findlay, J. W. (1961), Protecting frequencies for radio astronomy, URSI Information Bulletin, 124.

Findlay, J. W., (1961), Vertical incidence Doppler ionogram, Proc. IRE 49, 1220 .

Findlay, J. W. (1962), Protecting the science of radio astronomy, Science 13\%, 829.

Findlay, J. W., O. Struve, and R. M. Emberson (1960), The 140-foot radio telescope of the National Radio Astronomy Observatory, Publ. Astron. Soc. Pacific $\mathbf{7 \% ,} 439$.

Heeschen, D. S. (1960), A color-absolute magnitude diagram for extragalactic radio sources, Publ. Astron. Soc. Pacific 7\%, 368 .

Heeschen, D. S. (1961), Observations of radio sources at four frequencies, Ap. J. 133, 322.

Heeschen, D. S. (1961), Radio observations of galaxies, Publications of the NROA 1, 129 .

Heeschen, D. S., (1962), Annual Report-National Radio Astronomy Observatory, Astron. J. 6\%, No. 10.

Heeschen, D. S. (1962), Radio galaxies, Scientific American 206, 41 .

Heeschen, D. S., and B. L. Meredith (1961), Observations of discrete sources at $10 \mathrm{~cm}$ and $40 \mathrm{~cm}$ wavelengths, Publications of the NRAO 1, 121 .

Heeschen, D. S., and B. L. Meredith (1961), Secular variation of the flux density of the radio source Cassiopeia A, Nature 190, 705 .

Hobbs, R. W. (1961), A study of the region of M17 at a wavelength of $3.75 \mathrm{~cm}$, Astron. J. 66, 1294.

Hogg, D. E. (1962), An investigation of the radio emission from an ionized hydrogen complex in Cassiopeia, Thesis, University of Toronto. 
Kahn, F. D. (1961), Sound waves trapped in the solar atmosphere I., Ap. J. 134, 343.

Kahn, F. D. (1962), Sound waves trapped in the solar atmosphere II., Ap. J. 135, 547.

Kahn, F. D., and T. K. Menon (1962), Evolution of gaseous nebulae, Proceedings of the NAS 4\%, 1712.

Lynds, B. T. (1962), Catalogue of dark nebulae, Ap. J. Supp. Ser. $\boldsymbol{\gamma}, 1$.

Lynds, C. R. (1961), Observations of H II regions at 1400 Mc, Publications of the NRAO 1, 43.

Lynds, C. R. (1961), Observations of planetary nebulae at centimeter wavelengths, Publications of the NRAO 1, 85.

Lynds, C. R. (1961), Radio observations of M31 at $1400 \mathrm{Mc}$, Publications of the NRAO 1, 112.

Lynds, C. R. (1961), Radio observations of the peculiar galaxy M82, Ap. J. 134, 659.

Lynds, C. R., and S. Sobieski (1961), Observations of the Perseus cluster of galaxies at 3000 Mc, Publications of the NRAO 1, 155 (1961).

Menon, T. K. (1961), A model of the Orion nebula derived from radio observations, Publications of the NRAO 1, 1.

Menon, T. K (1962), A study of the Rosette nebula NGC 2237-46, Ap. J. 135, 394.

Menon, T. K. (1962), Physical conditions in the Orion nebula, Ap. J. 136, 95.

Orhaug, T. (1962), The effect of atmospheric radiation in the microwave region, Publications of the NRAO 1, 215.

Orhaug, T., and W. Waltman (1962), A switched load radiometer, Publications of the NRAO 1, 179.
Osterbrock, D. E., and R. E. Stockhausen (1962), Photometry and radiometry of gaseous nebulae, Ap. J. 133, 2.

Struve, O., On the evolution of galaxies, Symposium on Stellar Evolution, La Plata Observatory, Argentina, p. 291.

Struve, O. (1961), Annual Report-National Radio Astronomy Observatory, Astron. J. 66, 465.

Terzian, Y. (1962), A study of the California nebula at 750 $\mathrm{Mc} / \mathrm{s}$, Publications of the NRAO 1, 205.

von Hoerner, S. (1961), The search for signals from other civilizations, Science 134, 1839.

von Hoerner, S. (1961), Very large antennas for the cosmological problem I. Basic considerations, Publications of the NRAO 1, 19.

von Hoerner, S. (1961), Very large antennas for the cosmological problem II. Reflecting cross antenna, Publications of the NRAO 1, 63 .

Wade, C. M. (1960), A possible new radio galaxy in the Virgo Cluster, The Observatory 80, 235.

Wade, C. M. (1962), Radio Astronomy, Yearbook of MeGraw Hill, Encyclopedia of Science and Technology 433.

Wade, C. M. (1961), Some features of M84 and M87 observed at $10 \mathrm{~cm}$ wavelength, The Observatory $\mathbf{8 1 ,} 202$.

Wade, C. M. (1961), The structure of Fornax A, Publications of the NRAO 1, 99 .

Wanner, J. F. (1961), A contour map of IC 443 at $1400 \mathrm{Mc} / \mathrm{s}$, Publ. Astron. Soc. Pacific 73, 143.

Weinreb, S. (1962), An attempt to measure Zeeman splitting of the galactic $21 \mathrm{~cm}$ hydrogen line, Ap. J. 356, 1149.

Weinreb, S. (1962), A new upper limit to the galactic deuterium-to-hydrogen ratio, Nature 195, 367.

\section{Ohio State University Radio Observatory, Columbus, Ohio}

Instrumental development. Construction of $260 \mathrm{ft}$ of the standing parabola tiltable flat reflector radio telescope has been completed through support from the National Science Foundation [Kraus, Nash, and Ko, 1961]. The antenna consists of a $360-$ by $70-\mathrm{ft}$ fixed standing paraboloid and a 260- by $100-\mathrm{ft}$ tiltable flat reflector, giving a usable aperture area of $18,200 \mathrm{ft}^{2}$. The antenna has been operated at frequencies from 20 to $2500 \mathrm{Mc} / \mathrm{s}$. At $2000 \mathrm{Mc} / \mathrm{s}$ the antenna has half-power beam widths of 7 by 26 min of arc in right ascension and declination.

Receivers have been constructed for simultaneous operation at 600 and $1400 \mathrm{Mc} / \mathrm{s}$ (continuum) and other receivers are under construction for additional frequencies. The $1400 \mathrm{Mc} / \mathrm{s}$ receiver has a parametric preamplifier giving an rms receiver noise of $0.1{ }^{\circ} \mathrm{K}$ with a 14 sec time constant. A digital output system has been developed for data processing and storage purposes. The new radio telescope has been in operation since November 1962 at 600 and $1400 \mathrm{Mc} / \mathrm{s}$ for study of discrete sources and general background mapping.

Theory of radıo telescope antennas. The interaction of statistical radio radiation with radio antennas has been studied, and the response of an elliptically polarized antenna to a quasi-monochromatic, partially polarized radio wave treated using coherence theory $[\mathrm{Ko}, 1962]$ and other techniques $[\mathrm{Ko}, 1961 \mathrm{a}]$. Various antenna parameters essential in the interpretation of radio telescope records are defined and their relations established $[\mathrm{Ko}, 1961 \mathrm{~b}]$. In particular, an analytical solution was derived for determining the disk temperature and the flux density of an extended radio source using pencil beam antennas.

Cygnus and M31 maps. Maps of the Cygnus region at $1400 \mathrm{Mc} / \mathrm{s}$ (Menon, 1963) and M31 at 600 and $1400 \mathrm{Mc} / \mathrm{s}$ [Kraus, 1963] are being prepared from observations with the $260-\mathrm{ft}$ telescope. The high resolution of the telescope at $1400 \mathrm{Mc} / \mathrm{s}$ reveals much interesting fine structure.

Radio studies of emission nebulae. During 1962 Menon published two studies based on observations he made before he joined the O.S.U. staff. These involve the Rosette nebula [Menon, 1962a] and the Orion nebula [Menon, 1962b]. Comparison of the density distribution in the Rosette nebula and the Orion nebula suggests certain characteristic differences in the possible modes of formation of the associated clusters.

Radio star scintillation. Observations of Cygnus A scintillation at $945 \mathrm{Mc} / \mathrm{s}$ were made continuously over a period of one year [Ko, 1960] using the O.S.UU. steerable $40-\mathrm{ft}$ parabolic dish antenna. The scintillation is strongest near the horizon and amplitude scintillation greater than 10 percent was observed at low altitude angles for 71 percent of the total observations. The scintillation characteristics are markedly affected by the presence of aurorae. The frequency of occurrence of scintillation follows a seasonal variation having two maxima, one in the winter and the other in the summer.

Earth satellite observations. A statistical study of the satellite ionization phenomenon has been made [Kraus and Tiuri, 1962]. The satellite-induced ionization appears to peak at the time of near 
approach of the satellite or somewhat before with most effects occurring in the interval of $20 \mathrm{~min}$ before to $10 \mathrm{~min}$ after the satellite's passage.

\section{Bibliography}

Ko, H. C. (1960), Amplitude scintillation of a radio star at ultra-high frequency, Proc. IRE 48, 1871.

Ko, H. C. (1961), On the analysis of radio astronomical observations made with high resolution radio telescope antennas, Ohio State University Radio Observatory Report 21.

Ko, H. C. (1961), On the determination of the disk temperature and the flux density of a radio source using high gain antennas, IRE Trans. AP-9, 500.
Ko, H. C. (1961), On the response of a radio antenna to complex radio waves, Proceedings of the National Electronics Conference 1\%, 500.

Ko, H. C. (1962), On the reception of quasi-monochromatic, partially polarized radio waves, Proc. IRE 50, 1950.

Kraus, J. D., R. T. Nash, and H. C. Ko (1961), Some characteristics of the Ohio State University 360 -foot radio telescope, IRE Trans. AP-9, 4.

Kraus, J. D., and M. E. Tiuri (1962), Observations of satelliterelated ionization effects between 1958 and 1960, Proc. IRE 50, 2076.

Menon, T. K. (1962), A study of the rosette nebula NGC 2237-46, Ap. J. 135, 394.

Menon, T. K. (1962), Physical conditions in the Orion nebula, Ap. J. 136, 95.

\section{Stanford Radio Astronomy Institute, Stanford, Calif.}

Work at Stanford Radio Astronomy Institute included investigations of large antennas and theoretical studies connected with various questions of astronomical observing.

Picken and Swarup modified the spectroheliograph by the addition of two equatorial $10-\mathrm{ft}$ paraboloids to produce $0.9^{\prime}$ east-west and $1.5^{\prime}$ north-south fan beams and obtained high-resolution polarization data for solar active regions. Solar maps taken daily with the $3^{\prime} \times 3^{\prime}$ pencil beam were published by the National Bureau of Standards, and special maps were furnished in connection with eclipse and rocket observations. The spectrum of the slowly varying component of solar radio emission associated with sunspot groups was determined by combining highresolution observations obtained at Stanford at $9.1 \mathrm{~cm}$ with those obtained at Sydney, Ottawa, and Nagoya at wavelengths of $21,10.7,7.5$, and $3.2 \mathrm{~cm}$.

The moon was investigated with a $2.3^{\prime} \times 2.5^{\circ}$ fan beam in various position angles at $9.1 \mathrm{~cm}$; the center-to-limb variation was compatible with that expected for a smooth surface with dielectric constant 1.1 to 1.2 . The brightness temperature varied as the square root of the cosine of the latitude. The surface of the moon, to a depth of at least several meters, has a porosity of 80 to 95 percent.

Observations of Vir A, Cen A, Tau A, Sag A, Orion nebula, and Omega nebula were made with a wide-band parametric amplifier $\left(\triangle T=0.1^{\circ} \mathrm{K}\right)$ and a $2.3^{\prime}$ fan beam, some detail being resolved in almost each case. The central part of Cen A was resolved into two components separated by $4.8^{\prime}$ east-west. The north-east component was found to be 15 percent polarized. Observations of $\mathrm{Cyg} \mathrm{A}$ with a $0.9^{\prime}$ fan beam gave a first direct measurement of the separation of the two concentrations.

Interest in satellite observations was continued.

\section{Bibliography}

Bracewell, R. N. (1960), Antenna tolerance theory, from Radio Wave Propagation, p. 179, W. C. Hoffman, editor (Pergamon Press, London).

Bracewell, R. N. (1960), Correcting noise maps for beamwidth from the radio noise spectrum, p. 141, D. H. Menzel, editor (Harvard University Press, Cambridge, Mass.).
Bracewell, R. N. (1961), Interferometry and the spectral sensitivity island diagram, IRE Trans. Ant. Prop. AP-9, 59.

Bracewell, R. N. (1961), Large radio telescopes, Astronomical Society of Pacific, Leaflet 389, 1.

Bracewell, R. N. (1961), Radio telescopes; today and tomorrow, IRE Student Quarterly $\boldsymbol{\gamma}, 25$.

Bracewell, R. N. (1961), Tolerance theory of large antennas IRE Trans. Ant. Prop AP-9, 49.

Bracewell, R. N. (1962), Antennas and data processing, IRE Trans. Ant. Prop. AP-10, 108.

Bracewell, R. N. (1962), A corrected formula for the spectral sensitivity function in radio astronomy, Australian J. Phys. 15, 445 .

Bracewell, R. N. (1962), Radio astronomy techniques, Handbuch der Physik 54 (Springer, Berlin).

Bracewell, R. N. (Jan. 1963), Correction for grating response in radio astronomy, Ap. J. 13\%.

Bracewell, R. N. (1962), Correction of spectroscopic line profiles for instrumental broadening, Proc. Phys. Soc. 99 , 1298.

Bracewell, R. N. (1962), Electrical scanning and low pass filtering in radio astronomy, Australian J. Phys. 15, 447.

Bracewell, R. N. (1962), How large can a microwave antenn be?, Microwave J. 5, 57.

Bracewell, R. N., B. F. C. Cooper, and T. E. Cousins (1962 Polarization in the central component of Centaurus A, N8 ture 195, 1289.

Bracewell, R. N., G. Swarup, and C. L. Seeger (1962), Futu large radio telescopes, Nature 193, 412.

Colvin, R. S. (1961), A Study of radio astronomy receivers, Stanford Radio Astronomy Institute Publication No. 18A.

Carriott, O., and R. N. Bracewell (1961), Satellite studies of the ionization in space by radio, Advances in geophysics H. E. Landsberg, editor (Academic Press, New York).

Kakinuma, T., and G. Swarup (1962), A model for the sources of the slowly varying component of microwave solar radiation, Ap. J. 136, 975.

Little, A. G. (1963), Observations at $9.1 \mathrm{~cm}$ of Taurus A the Orion nebula, Virgo A, Centaurus A, Sagittarius A and the Omega nebula with a 2.3 minute-of-are fan beam Ap. J. $13 \%$.

Swarup, G. (1961), Mills cross and related pencil-bear antennas, IRE NEREM Record $\mathbf{9 0 .}$

Swarup, G., T. Kakinuma, A. E. Covington, G. A. Harvey R. F. Mullaly, and J. Rome, High resolution studies of tee solar active regions at wavelengths of 3 to $21 \mathrm{~cm}$, Ap. J. (in press).

Swarup, G., and K. S. Yang (1960), Monitoring paraboloidal reflector antennas, Proc. IRE 48, 1918.

Swarup, G., and K. S. Yang (1961), Phase adjustment of large antennas, IRE Trans. Ant. Prop. AP-9, 75.

Zisk, S. H., and R. A. Fish (1963), A direct analyzer for stellar images, App. Opt. 2, 31.

Solar Geophysical Data, National Bureau of Standards Boulder, Colo., Series CRPL-F Part B, 196, 197, 19 ! 210-220 (1960-1962). 


\section{University of Texas, Austin, Tex.}

The investigation of extraterrestrial radiation by the Electrical Engineering Research Laboratory of the University of 'Texas between the wavelengths of 4.3 and $2.15 \mathrm{~mm}$ has been restricted to solar, lunar, and planetary measurements because of the nature of detectable levels of emission at these wavelengths. Attempts have been made to detect and measure $4.3 \mathrm{~mm}$ radiation from Cygnus $\mathrm{X}, \mathrm{A}$, and $\mathrm{B}$, Cassiopeia $\mathrm{A}$, and the nebula of Orion with negative results. The upper limit of the level of emission from these "radio stars" has been set at approximately $10^{-22} \mathrm{w} \mathrm{m}^{-2}(\mathrm{c} / \mathrm{s})^{-1}$ at $4.3 \mathrm{~mm}$ as a result of the observations.

Sixty-inch searchlight type antennas have been used successfully over the interval of 4.3 to $2.15 \mathrm{~mm}$ for the measurement of solar and lunar radiation levels. The radio telescope currently being used to monitor the distribution of brightness over the solar disk has a nominal antenna beamwidth of $9 \mathrm{~min}$ of arc at the observing wavelength of $3 \mathrm{~mm}$.

Observations of solar emission at $4.3 \mathrm{~mm}$ were made during the 15 February 1961 solar eclipse from a site near Pisa, Italy, with a radio telescope mounted on a flatbed truck. Measurements of $4.3 \mathrm{~mm}$ lunar emission over the period of a lunation and during the 25 August 1961 lunar eclipse were made simultaneously with the truck-mounted radio telescope located near Huntsville, Ala., and a radio telescope located at Austin, Tex. Mobility of the radio telescope is desirable in order to allow relatively easy placement of the instrument at locations from which astronomical events can be observed and to permit a rapid change of location in case of predicted inclem- ent weather. A similar millimeter wavelength truckmounted radio telescope of "improved design" is being assembled to observe the July 1963 solar eclipse.

A construction contract, supported by the National Aeronautics and Space Administration, has been let with the Philco Corporation to fabricate and install at the Electrical Engineering Research Laboratory a 16 -ft diam antenna with a parabolic surface figured for useful operation at wavelength of $2 \mathrm{~mm}$. Installation of the antenna and astrodome housing is scheduled to be completed by the first quarter of 1963. The antenna is expected to provide a capability for measuring the planetary emission levels at the "window frequencies" of the earth's atmosphere between $1 \mathrm{~cm}$ and $2 \mathrm{~mm}$ wavelengths. The antenna will also have a useful higher degree of resolution of the emission from areas of the moon. The larger capture area is also expected to provide a capability for detecting celestial emission levels.

\section{Bibliography}

Tolbert, C. W., L. C. Krause, and R. M. Dickinson, Lunar radiation at $4.3 \mathrm{~mm}$ during the 25 August 1961 eclipse and the lunar model, The Aeronautical Electronics $1962 \mathrm{Na-}$ tional Conference Proceedings.

Tolbert, C. W., and A. W. Straiton (May 1962), Observations of $4.3 \mathrm{~mm}$ radiation during the solar eclipse of 15 February 1961, Ap. J.

Tolbert, C. W., and A. W. Straiton (1961), Solar emission at millimeter wavelengths, Ap. J. 13491.

Tolbert, C. W., A. W. Straiton, and L. C. Krause (1960), The investigation of celestial emission at $4.3 \mathrm{~mm}$ radio wavelength, EERL Report 5-43, The University of Texas.

\section{U.S. Naval Research Laboratory, Washington, D. C.}

\section{Organization and Facilities}

The Radio Astronomy Branch consists of four sections, including three groups working principally in planetary, galactic, and extragalactic observations of brightness and polarization, and one group devoted to radar astronomy, principally lunar range measurements. Observational work is carried on at the main station of the Laboratory and at Maryland Point Observatory on the north shore of the Potomac River in Charles County, Md. The principal observational instruments are an $84-\mathrm{ft}$ equatorial reflector useful to wavelengths of $10 \mathrm{~cm}$, located at Maryland Point, and two solid-surface reflectors at the main laboratory, one a $50-\mathrm{ft}$ altazimuth reflector useful to wavelengths less than 2 $\mathrm{cm}$, and the other a $10-\mathrm{ft}$ equatorial reflector useful at wavelengths as short as $4 \mathrm{~mm}$.

Several changes have taken place in the personnel named in previous reports. C. M. Bowden resigned to enter a teaching post at University of Richmond, and C. R. Grant and F. Wrigley transferred to Goddard Space Flight Center of NASA.
The Branch was joined by B. L. Gary from University of Michigan, by S. Knowles from the Naval Observatory, by D. L. Hammond and R. E. Morden from Sound Division, MRL, and by J. P. Hollinger from George Washington University.

\section{Programs}

Further observations have been made by Mayer, McCullough, and Sloanaker with the 50-ft reflector to investigate the polarization of the radiation from the strongest discrete sources at wavelengths of 3.15 , 3.47 , and $9.4 \mathrm{~cm}$. The measurements were made using rotating, linearly polarized, horn feed antennas at the focus of the reflector, which permitted only linearly polarized components of the radiation to be distinguished.

At $3.15 \mathrm{~cm}$, strong, linearly polarized components were observed for Cygnus $A$, Centaurus $A$, and the Crab nebula. The measurements show partial linear polarization of about 8 percent at a position angle of approximately $143 \mathrm{deg}$ for Cygnus A, about 13 percent at $144 \mathrm{deg}$ position angle for Centaurus A, and 
substantiate the value of about 7 percent linear polarization for the Crab nebula at $143 \mathrm{deg}$ position angle as determined from previous measurements with the 50-ft reflector. In addition, several other sources were investigated at $3.15 \mathrm{~cm}$ which showed no measurable polarization, and the quality of the observations for these sources set upper limits for the fraction of linear polarization at about $1 / 2$ percent for Cassiopeia $\mathrm{A}$, and 1 percent for the Orion nebula, the Omega nebula, Virgo A, and Sagittarius A, and of about 3 percent for the planet Venus.

The observations at $9.4 \mathrm{~cm}$ wavelength substantiate previous measurements at wavelengths near $10 \mathrm{~cm}$ of a linearly polarized component of 3 to 4 percent of the total radiation from the Crab nebula, and confirm the earlier negative results with an upper limit of roughly 1 percent for linear polarization for both Cassiopeia A and Cygnus A. An upper limit of 1 percent was put on the degree of of polarization of Virgo A, but Centaurus A gave a result of 7 percent at $121^{\circ}$ at this wavelength.

A solid-state maser amplifier at $9.4 \mathrm{~cm}$ wavelength designed by W. K. Rose of the Columbia University Radiation Laboratory and NRL, followed by a superheterodyne radiometer designed by J. M. Bologna and Rose was installed on the 84 -ft reflector in June 1962. The maser is operated at a bandwidth of about $18 \mathrm{Mc} / \mathrm{s}$ and a gain of about 20 db. The IF bandwidth of the radiometer is 20 $\mathrm{Mc} / \mathrm{s}$. The equivalent noise temperature of the system is about $95^{\circ} \mathrm{K}$, including an estimated $25^{\circ} \mathrm{K}$ background noise picked up by the antenna. The rms output fluctuation is $0.013^{\circ} \mathrm{K}$ with a 7 -sec receiver integration time.

Observations with this equipment were made by Rose, Bologna, and Sloanaker during the months July-October 1962. Flux and linear polarization measurements, using a rotating, plane-polarized, feed-antenna, were made of a number of radio sources listed in the Third Cambridge Catalogue, and of the planets Jupiter and Saturn. The following results were obtained at $9.4 \mathrm{~cm}$ wavelength for the degree of linear polarization and position angle of the $E$-vector of the polarized component for six sources: $3 \mathrm{C}-295,3.4$ percent \pm 0.9 percent (pe) at $168^{\circ} \pm 15^{\circ}$ (pe) ; Hercules - A, 9.0 percent \pm 1.6 percent at $36^{\circ} \pm 10^{\circ} ; 3 \mathrm{C}-433,5.9$ percent \pm 1.9 percent at $128^{\circ} \pm 18^{\circ} ; 3 \mathrm{C}-48,4.2$ percent \pm 1.2 percent at $60^{\circ} \pm 16^{\circ} ; 3 \mathrm{C}-286,7.4$ percent \pm 1.7 percent at $45^{\circ} \pm$ $12^{\circ}$; and $3 \mathrm{C}-147,4.0$ percent \pm 0.8 percent at $94^{\circ} \pm$ $11^{\circ}$. Observations of the $9.4 \mathrm{~cm}$ radiation from Jupiter established that during the observing period the degree of linear polarization was 21 percent, the positions of the magnetic poles with respect to System III were $190^{\circ}$ and $10^{\circ}$, the angle of tilt between the magnetic axis and the rotational axis was $12^{\circ}$, and the mean equivalent blackbody disk temperature was $658{ }^{\circ} \mathrm{K} \pm 39^{\circ} \mathrm{K}$ (pe). Measurements on Saturn during the same period indicate that the $9.4 \mathrm{~cm}$ radiation is linearly polarized with the maximum $E$-vector direction nearly parallel to the axis of rotation in contrast to Jupiter where the $E$-vector maximum is more nearly parallel to the equator.
The measured, equivalent blackbody disk temperatures for Saturn were $141{ }^{\circ} \mathrm{K} \pm 20^{\circ} \mathrm{K}$ (pe) for the $E$-vector parallel to the planet's rotational equator, and $213^{\circ} \mathrm{K} \pm 18^{\circ} \mathrm{K}$ (pe) for the $E$-vector perpendicular to the equator. The measurements give a lower limit for the degree of linear polarization of 20 percent \pm 8 percent (pe).

A search for $3.15 \mathrm{~cm}$ wavelength, circularly polarized radiation from discrete sources was made during the months of October and November 1962 using the 50-ft reflector by C. H. Mayer and J. P. Hollinger of the Radio Astronomy Branch and P. J. Allen of the Tracking Radar Branch. No evidence for circular polarization within the error limits of the experiment was found for the eight sources observed. The observations established upper limits for the percentage circular polarization of less than 1 percent for the sources Cassiopeia $\mathrm{A}$ and Taurus A; less than 2 percent for the Omega nebula, Orion nebula, Cygnus A, and Sagittarius A; and less than 5 percent for Centaurus $\mathrm{A}$ and Virgo $\mathrm{A}$.

The series of observations of the $3.15 \mathrm{~cm}$ radiation from Venus which were begun early in March 1961 by Mayer, McCullough, and Sloanaker using the 50 -ft reflector were continued through August 1961. The observations were spread over a considerable range of phase angle of solar illumination of from about $118 \mathrm{deg}$ before the inferior conjunction of April 11 th to about $54 \mathrm{deg}$ after conjunction, and were made primarily for the purpose of more accurately defining the dependence of the average radio brightness over the disk on the phase angle, which had been inferred from earlier $3.15 \mathrm{~cm}$ observations using the $50-\mathrm{ft}$ reflector. The measurements were made with a superheterodyne radiometer similar to those previously used to measure Venus with this reflector, but with improved sensitivity by a factor of about 2 .

The observations show that the equivalent blackbody disk temperature of Venus varies with the phase of solar illumination in essentially the wav suggested by the earlier measurements. A good representation of the data is obtained by fitting it to the first two terms of a Fourier series, $T_{b b}=\left\langle T_{b b}\right\rangle$ $+\chi \cos$ (phase angle $-\theta$ ). The time-average value of the blackbody disk temperature $\left\langle T_{b b}\right\rangle$ is approximately $630^{\circ} \mathrm{K}$, and the most probable value of the amplitude $\chi$ is between about 70 and $90^{\circ} \mathrm{K}$. The observations show that the minimum disk temperature occurs at a phase angle of about $12 \mathrm{deg}$ after inferior conjunction; this phase lag suggests that the rotation period of Venus is not the same as the orbital period, and that the rotation is retrograde.

The observations of Venus at $4.3 \mathrm{~mm}$ by Grant and Corbett during the 1961 conjunction period yielded a mean value for brightness temperature of $350^{\circ} \mathrm{K}$ with an uncertainty of $+50^{\circ} /-30^{\circ}$ probable error. No evidence could be detected of a phase dependence. Earlier measurements at $8.6 \mathrm{~mm}$ by Gibson during the 1959 conjunction were found to give $410{ }^{\circ} \mathrm{K}$ with an uncertainty of $+30^{\circ} /-20^{\circ}$ probable error. These millimeter-wave results are mutually compatible, and indicate the need for data in the 1 to $3-\mathrm{cm}$ range, wherein lies the transition to 
the higher brightness temperatures of the centimeter range.

Gibson and Corbett carried out an extensive observational program at $1.35 \mathrm{~cm}$ wavelength on Venus during the 1962 conjunction. The mean brightness temperature indicated by several representative occasions is $520^{\circ} \mathrm{K}$, with a probable error of $\pm 40^{\circ}$. Additional data not yet reduced may slightly increase this temperature value. Since 1.35 $\mathrm{cm}$ is the principal water vapor resonance and since the temperature measured was not significantly different from adjacent wavelengths it may be concluded that water vapor if present is not abundant, or alternately, that the water vapor is at an elevated temperature.

During August and September of 1961, A. C. Miller and B. L. Gary measured the continuum radiation from Jupiter at $1440 \mathrm{Mc} / \mathrm{s}(20.8 \mathrm{~cm})$. Measurements were made on 16 nights in August with the feed horn polarized favorably (roughly parallel to Jupiter's equator) with respect to the polarized component of radiation, and on 17 nights in September with the horn in the orthogonal, or unfavorable, position. The average equivalent blackbody temperatures recorded for the two series were 3630 ${ }^{\circ} \mathrm{K} \pm 300^{\circ} \mathrm{rms}$ and $2190^{\circ} \mathrm{K} \pm 400^{\circ} \mathrm{rms}$, respectively. The data can be reasonably interpreted to indicate a degree of linear polarization of 25 to 45 percent, which is compatible with 33 percent polarization reported by Radhakrishnan and Roberts at $960 \mathrm{Mc} / \mathrm{s}$ and 28 percent reported by Morris and Berge at $1390 \mathrm{Mc} / \mathrm{s}$. Variations in disk temperature were observed, which are consistent with the previous observations made in 1959 at $1430 \mathrm{Mc} / \mathrm{s}$ by McClain, Nichols, and Waak, who suggested a correlation with rotation of the planet. Support for this correlation with rotation is given by Morris and Berge who made measurements at $1390 \mathrm{Mc} / \mathrm{s}$ that argue for a model in which Jupiter's magnetic poles are inclined about $9^{\circ} \pm 3^{\circ}$ with respect to the planet's rotational axis, and located at $20^{\circ} \pm 10^{\circ}$ and $200^{\circ} \pm 10^{\circ}$ System III longitude $\left(9^{\mathrm{h}} 55^{\mathrm{m}} 29^{\mathrm{s}} .35\right)$. Least-square analysis of our data shows a consistency with the above model, and indicate that the magnetic pole near $20^{\circ}$ longitude is located in the northern hemisphere. Future instrumentation will be designed to measure linear polarization on an hour-to-hour basis.

Earlier measurements of Jupiter at $1440 \mathrm{Mc} / \mathrm{s}$ were made during May, June, and July 1960 by A. C. Miller, when unfortunately Jupiter's position was in the galactic plane, greatly complicating the data reduction. However, it is hoped that at least a mean temperature value for the north-south polarization during that period will be obtainable.

The mean distance to the moon was reported by the U.S. Naval Research Laboratory from radar measurements taken over one month in 1957. This value was obtained by neglecting a time varying effect between the measured and calculated daily distance measurements. It was believed that this effect is related to the topographic features of the moon, and that if this could be established, the value of the mean distance to the moon might be improved.
However, due to the large scatter of the residuals (radar distance minus calculated distance) and the limited number of observations, the variations could not be consistently explained.

In order to determine the effects of the residual variations on the mean distance correction, an extended lunar radar observation program was initiated in October 1959 and continued to July 1960 by B. S. Yaplee, S. H. Knowles, A. Shapiro, K. J. Craig of NRL, and C. Brouwer of Yale University Observatory. It was planned to obtain redundant measurements from specific reflecting areas. This is possible because as observations are taken over several lunar months, the center of the radar beam traces similar elliptical paths on the lunar surface. This redundancy permits one to determine the radar heights of these areas on the moon, and possibly show a relationship with optical topography.

It was possible to associate several observations separated by one or more months with particular areas on the moon's surface. These were then averaged over 1 deg selenographic squares and plotted as a map. The derived radar map shows some correlation with the optical map obtained from the Army Map Service. Though some correlation is noted, it is not as much as had been expected. This result must be accepted with caution, as the accuracy of the optical map is less than the potential accuracy of the radar map, and the actual reflecting areas are difficult to establish.

The scatter of the daily measurements was considerably reduced by improving the radar system performance and using longer integration times for each observation. However the basic accuracy of the measurement technique was still limited by the uncertainty of the position of the leading edge of the echo as it emerged from the noise level. Furthermore, even though the spread of the radar measurements from the same general area was in most cases comparable to the daily scatter, a few observations exceeded the daily spread. The causes for this large scatter are now being investigated. Even though these limitations will add some uncertainty to the final result, there is sufficient evidence to justify the use of the radar map for refining the mean lunar distance. Using the best known constants, including $1738 \mathrm{~km}$ for the moon's radius, and applying radar topographic corrections to the residuals, a value of $384,400,400 \pm 1200 \mathrm{~m}$ was obtained for the mean distance to the moon. Due to the large error estimate which is almost entirely due to the uncertainty of $1 \mathrm{~km}$ in the moon's radius, the radar topographical corrections did not affect the mean distance significantly. The mean distance reported here will be proposed to the IAU Symposium No. 21 "The System of Astronomical Constants" to be adopted as a constant.

J. Waak of NRL and Dr. Nancy G. Roman of NASA are analyzing 3-color photoelectric photometry observations made chiefly in 1958 by Miss Roman (then of NRL) at McDonald Observatory. The observations cover stars brighter than $\mathrm{m}_{\mathrm{pg}}=12.0$ in certain of Kapteyn's Selected Areas as well as several 
other regions. The Selected Areas which have been observed are SA 9, 13, 14, 15, 29, 30, 31, 32, 33, 34, $35,53,56,54,55,57,58,59,60,64,74,78,79,80$, $81,82,83,87,98,102,103,104,105,106,110,128$, and 129. Selected stars in the Hamburg catalogue as well as high-latitude $\mathrm{K}$ stars observed spectroscopically by Edmondson, and certain high-latitude giants selected by Luis Munch from Tonanzintla plates have also been observed. The main purpose of this program is to determine if an ultraviolet "excess" can be conveniently used as an observational population discriminant.

\section{Instrumentation}

The design and development of modifications to to the SECASI-NRL telescopes for making photometric measurements of $\mathrm{H} \alpha$ emission from the sun and Jupiter is being continued by Edelson and Santini. The optical and mechanical components are in their final stages of assembly. Design of supporting electronic equipment for the receiver and planetary guidance systems is proceeding according to plan. Two photomultiplier tubes that were tested were rejected because of too low response at the operating wavelength. Preliminary measurements of a third 9558 photomultiplier indicates that the tube is acceptable, having a radiant sensitivity of $2.74 \times 10^{-2} \mu \mathrm{A} / \mu \mathrm{W}$ at $\lambda 6563$. The facilities for mounting the telescopes at Maryland Point Observatory have been completed.

Under supervision of James E. Kenney, the surface of the $84-\mathrm{ft}$ radio telescope was recently adjusted by D. S. Kennedy so that the maximum target error was $9 \%$ of an inch. Subsequent measurement revealed the aperture efficiency to be substantially unchanged at 40 to 45 percent. This finding lends some weight to the possibility that mesh surfaces act in some not understood way and that high efficiency approaching 60 to 65 percent is not possible with this type surface. Consideration is being given to replacing the mesh with sheet metal to test the matter further.

A double Dicke radiometer has been designed and built by E. F. McClain and James E. Kenney. The receiver employs high quality isolators built by Melabs, Palo Alto, Calif., and a double pole double throw diode switch of excellent quality provided by Microwave Associates. The IF frequency extends from $8.5 \mathrm{Mc} / \mathrm{s}$ to $11.5 \mathrm{Mc} / \mathrm{s}$ so that all open bands are in the hydrogen line frequency allocation. Low pass filters are employed to eliminate any $10 \mathrm{~cm}$ radar signals. The receiver will be used with a rotating feed horn for polarization studies.

\section{Bibliography}

Alsop, L., and J. A. Giordmaine (June 1, 1961), The observation of three centimeter radiation from astronomical objects with a ruby maser, Columbia University Report.
Edelson, S. (1961), A study of long and short term variations in solar radiation at radio and optical wavelengths, Dissertation, Georgetown University.

Edelson S. (1962), Calculations of a slowly varying component at $4.3 \mathrm{~mm}$, Astrophys. J. 135, No. 3.

Gibson, J. E. (May 1961), Lunar surface characteristics indicated by the March 1960 eclipse and other observations, Ap. J. 133, No. 3.

Gibson, J. E., The brightness temperature of Venus at 8.6 mm, Astrophys. J. (in press, Jan. 1963)

Gibson, J. E., and H. H. Corbett, The brightness temperature of Venus at $1.35 \mathrm{Cm}$, Abstract, Astron. J. (in press).

Grant, C. R., and H. H. Corbett (Mar. 1962), Observations of Venus at $4.3 \mathrm{~mm}$, Abstract, Astron. J. 6\%, No. 2.

Grant, C. R., H. H. Corbett, and J. E. Gibson, Measurements of the $4.3 \mathrm{~mm}$ radiation of Venus, Astrophys. J. (in press, Feb. 1963)

Mayer, C. H., An introductory review on the radio emission of the planets, Space Research III (North-Holland Publishing Co., Amsterdam) (in press).

Mayer, C. H., General report on planetary radio astronomy, Proc. of the 11th International Astrophysical Symposium, Physics of the Planets (University of Liege, Liege, Belgium) (in press).

Mayer, C. H., Radio observations of the moon and planets, Triennial Report to the IUGG, American Geophysical Union (in press).

Mayer, C. H. (1961), Radio emission of the moon and planets, ch. 12, The solar system, Vol. III, Planets and Satellites, edited by G. P. Kuiper and B. M. Middlehurst (Chicago, Univ. of Chicago Press).

Mayer, C. H. (1962), Radio waves from the planets, Proc. of the Symposium on Radio Astronomy for Science Writers, Distributed by the American Institute of Physics.

Mayer, C. H. (1961), The temperatures of the planets, Scientific American 204, No. 58.

Mayer, C. H., T. P. McCullough, and R. M. Sloanaker, 3.15 $\mathrm{cm}$ observations of Venus in 1961, Proc. of the 11th International Astrophysical Symposium, Physics of the Planets (University of Liege, Liege, Belgium) (in press).

Mayer, C. H., T. P. McCullough, and R. M. Sloanaker (1962), Evidence for polarized $3.15 \mathrm{~cm}$ radiation from the radio galaxy Cygnus-A, Astrophys. J. 135, No. 2.

Mayer, C. H., T. P. McCullough, and R. M. Sloanaker (Nov. $1962)$, Polarization of the radio emission of Taurus-A, Cygnus-A and Centaurus A, Abstract, Astron. J. 67, No. 9.

Mayer, C. H., J. P. Hollinger, and P. J. Allen, A search for $3.15 \mathrm{~cm}$ wavelength circularly polarized radiation from discrete sources, Astrophys. J. (in press, May 1963).

McClain, E. F. (Nov. 1960), Report of observatories-U.S Naval Research Laboratory, Radio Astronomy Branch, Astron. J. 65, No. 9.

MeClain, E. F. (Nov. 1961), Report of observatories-U.S. Naval Research Laboratory, Radio Astronomy Branch, Astron. J. 66, No. 9.

McClain, E. F. (Nov. 1962), Report of observatories-U.S. Naval Research Laboratory, Radio Astronomy Branch, Astron. J. 6\%, No. 9.

McClain, E. F., J. H. Nichols, and J. A. Waak (Dec. 1962), An investigation of variations in the decimeter wave emission from Jupiter, Astron. J. 6\%, No. 10.

Miller, A. C., and B. L. Gary (Dec. 1962), Measurements of the decimeter radiation of Jupiter, Astron. J. 67, No. 10.

Rose, W. K., J. M. Bologna, and R. M. Sloanaker, Linear polarization of Jupiter, Saturn, and weak radio sources using a $9.4 \mathrm{~cm}$ maser, Abstract, Astron. J. (in press).

Rose, W. K., J. M. Bologna, and R. M. Sloanaker, Linear polarization of the $3200 \mathrm{Mc} / \mathrm{sec}$ radiation from Saturn, Physical Review Letters (in press).

Sloanaker, R. M., and J. W. Boland (Mar. 1961), Observations of Jupiter at a wavelength of $10 \mathrm{~cm}$, Astrophys. J. 133, No. 2.

Waak, J. A. (Sept. 1961), An investigation of possible variations in the brightness temperature of the moon at $21 \mathrm{~cm}$, Abstract, Astron. J. 66, No. 7. 


\section{Yale University, New Haven, Conn.}

Planetary investigations: Semicontinuous monitoring of the decameter spectrum primarily at 20 and $22.2 \mathrm{Mc} / \mathrm{s}$ with phase-switched, phase-sensitive-detecting interferometers has helped to establish the conclusion that Jupiter and the sun are the only strong solar system decametric sources. Only Saturn seems to be a likely further possibility above 20 $\mathrm{Mc} / \mathrm{s}$, and this only on rare and as yet doubtful occasions.

Douglas has analyzed our observations and those of most other observers to derive a definitive decametric rotation period for Jupiter, now adopted by the IAU: System III (1957.0) $P=9^{\mathrm{h}} 55^{\mathrm{m}} 29.37^{\mathrm{s}}$. He has shown that this period has not changed systematically by more than half a second over the decade 1951-1961, also that there is no evidence for irregular change as large as 2 or $3 \mathrm{sec}$.

We find that Jupiter's emission is concentrated in three longitude regions. Frequency-drifting burst groups have been demonstrated, the rate of drift being of the order of a megacycle per minute. The noise storms behave as though their radiation tended to fill an escape cone froin Jupiter coinciding roughly with the longitudes of central meridian over which the storms are heard, but with a tendency for sharp and discrete enhancements of the emission for periods of a few minutes up to an hour or more.

Spaced-receiver experiments with base lines up to $100 \mathrm{~km}$ have shown the presence of a rich pattern of very fine structure $(0.01$ to $1 \mathrm{sec})$ in the Jupiter (and occasionally the solar) decametric emissions, which ranges from perfect correlation in form and time down to several thousandths of a second at stations $100 \mathrm{~km}$ apart, to complete lack of correlation in form and time. We provisionally conclude that the very fine structure does not arise in the ordinary high ionospheric regions which produce the traditional radio-star scintillation, but rather in higher regions, perhaps at the boundary of the terrestrial magnetosphere. Certain drifting events which appear with time lags up to 1 sec between the stations may arise from interplanetary plasma clouds.

Polarization studies show that about 97 percent of the decametric storms at $22 \mathrm{Mc} / \mathrm{s}$ have dominant right-circular polarization. Left-circular polarization tends to occur at rare intervals, for durations of about $10 \mathrm{~min}$, and from the principal emission lobe of the planet.

The strongest storms seem to involve, for periods of several hours, about $10^{10} \mathrm{~W}$ of radiated decametric power above $5 \mathrm{Mc} / \mathrm{s}$, but a more reasonable average emission from the planet as a whole, over time, is probably about $10^{8} \mathrm{w}$-in the same energy range as the microwave emission.

Warwick's interpretation would imply that the noise storms should coincide with a type of activity which, on the earth, produces strong auroras; a very careful search in $\mathrm{H} \alpha$ has established that at least in the autumn of 1962 no mean auroral activity along 10-sec-of-arc portions of the limb of Jupiter was present with an average intensity as great as three times that of a strong terrestrial $\mathrm{H} \alpha$ aurora.
Nonplanetary investigations: The radio star 3C 48 was shown not to have been a nova, a supernova, or even a variable star with amplitude much greater than $0.4 \mathrm{mag}$. since 1897 .

Antenna and radiometer design and construction has been carried out toward the technique of using broad banding as a supplement to antenna directivity.

Observational problems currently under active investigation: Low-frequency ionospheric refraction and refraction anomalies; positions and motions of solar decametric source regions; synoptic monitoring of Jupiter and other possible sources; fine-structure analysis; study of polarization at several frequencies; establishing precise spectral indices at the lower frequencies; and determination of precise declination of the brighter radio sources.

\section{Bibliography}

Douglas, J. N. (1960), A uniform statistical analysis of Jovian decameter radiation, 1950-1960, Astron. J. 65, 487. Douglas, J. N. (1960), A study of non-thermal radio emission from Jupiter, Dissertation, Yale University.

Douglas, J. N. (1961), A broad-band interferometer for studies of discrete radio sources, Northeast Electronics Research and Engineering Meeting Record, p. 88.

Douglas, J. N. (1962), A statistical analysis of Jupiter's decameter radiation, 1950-61, Astron. J. 67, 574.

Douglas, J. N. (1963), Decametric radiation from Jupiter II. Statistics of period-determination and correlations, Astron. J. 68 (in press).

Douglas, J. N., Fine-structure problems in Jovian decametric radiation, in Physics of the Planet Jupiter (Benjamin Press) (in press, 1963)

Douglas, J. N., and C. C. Brooks (1962), A novel interferometer for studies of discrete radio sources, Astron. J. 67, 575 .

Douglas, J. N., and H. J. Smith (1961), Presence and correlation of fine-structure in Jovian decametric radiation, Nature 192, 741.

Douglas, J. N., and H. J. Smith, Decametric radiation from Jupiter I. Observations 1957-1961, Astron. J. 68 (in press, 1963).

Douglas, J. N., and H. J. Smith (1963), Observation bearing on the mechanism of Jovian decametric emission, Proceedings of the 11th Liege International Astrophysics Colloquium, Ann. Royal Society of Belgium (in press).

Oster, L., and K. W. Philip (1961), Existence of net electric charges on stars, Nature $\mathbf{1 8 9}, 43$.

Smith, H. J. (1962), Longitude effects in Jovian decametric radio emission, Astron. J. 67, 586.

Smith, H. J. (1962), Radio radiation from Jupiter, Notes for MIT Special Summer Program on Radio Astronomy.

Smith, H. J. (1963), ed., Physics of the Planet Jupiter, Proceedings of October 1962 NASA-Sponsored Conference (Benjamin Press, in press).

Smith, H. J., Summary of decametric emissions from Jupiter, in Physies of the Planet Jupiter (Benjamin Press) (in press, 1963).

Smith, H. J., and J. N. Douglas (1962), Fine-structure in Jovian decametric radio noise, Astron. J. 67, 120.

Smith, H. J., and D. Hoffleit (1961), Photographic history and suggested nature of the radio source 3C 48, Astron. J. 66, 295.

Smith, H. J., B. M. Lasker, and J. N. Douglas (1960), Finestructure of Jupiter's 20 Me noise storms, Astron. J. 65, 501.

Smith, H. J., J. P. Rodman, and W. A. Sloan, On Jovian Ha auroras, Astron. J. 68 (in press).

(Paper 68 D5-364) 